Revista de la red interuniversitaria de estudios sobre las literaturas rioplatenses contemporáneas en Francia

Prodigios borgeanos: ficciones, historias, teologías

\title{
Borges y el idioma de los franceses
}

\section{Magdalena Cámpora}

\section{CpenEdition}

Journals

Edición electrónica

URL: http://journals.openedition.org/lirico/2002

DOI: $10.4000 /$ lirico. 2002

ISSN: 2262-8339

Editor

Réseau interuniversitaire d'étude des littératures contemporaines du Río de la Plata

Referencia electrónica

Magdalena Cámpora, "Borges y el idioma de los franceses », Cuadernos LIRICO [En línea], 12 | 2015,

Puesto en línea el 23 enero 2015, consultado el 19 abril 2019. URL : http://journals.openedition.org/ lirico/2002 ; DOI : 10.4000/lirico.2002

Este documento fue generado automáticamente el 19 abril 2019.

\section{(c) (i) $(9)$}

Cuadernos LIRICO está distribuido bajo una Licencia Creative Commons Atribución-NoComercialSinDerivar 4.0 Internacional. 


\section{Borges y el idioma de los franceses}

\section{Magdalena Cámpora}

Para Michel Lafon, argentiniste, amigo

Roger Caillois abre su discurso de ingreso a l'Académie française en 1972 con el nombre

de Jorge Luis Borges.

No menciona, en ese marco de consagración institucional que entiende la lengua francesa como un patrimonio, a ningún otro autor extranjero ; sólo el nombre de Borges, que

Caillois invoca para ilustrar una relación afectiva con la lengua :

J'ai nourri durant mon adolescence une sorte de haine contre la littérature même, dont je prévoyais et souhaitais naïvement la disparition prochaine. [...] Pourtant, dès ces intransigeances de jeunesse, où la passion avait plus de part que la lucidité, se trouvaient déjà réunis, à mon insu, plusieurs éléments qui devaient plus tard se

révéler décisifs : en premier lieu, une attention, que dis-je ? une ferveur pour le langage, que j'entourais de soins quasi philatéliques comme dirait Jorge-Luis Borges 1 .

Dos años antes, en 1970, en las páginas delNew Yorker

, afirmaba sin embargo Borges, y en inglés : «French, rather paradoxically, has a fine

literature [...] but the language itself is, I think, rather ugly.

Things tend to sound trivial when they are said in French ${ }^{2} »(1970: 147)$.

¿Cómo entender, a la luz de estas declaraciones, la mención de autoridad bajo la Cúpula? Caillois, se sabe, es uno de los principales agentes de la introducción de Borges en Francia

, y bajo la sombra de ese mandato parece ignorar (o ignora) la ofensiva y sajona confesión a Di Giovanni. Por lo demás, Borges es incorporado en su discurso de forma abstracta : la metáfora filatélica sugiere una actitud afectiva con la lengua, de cuidado entre obsesivo y paciente, no carente de deseo, posible con cualquier lengua. Es decir : una relación con el francés en abstracto, que no se encarna y que sin embargo circula en el manejo de la proyección internacional de Borges. 
La anécdota ilustra eficazmente la relación de Borges con el idioma francés, que es a imagen y semejanza de su relación con la literatura francesa : a la vez ambigua y productiva. Por un lado el rechazo público, ratificado por la crítica (el « Borges francófobo » (1989) de Saer hace las veces de acta fundacional) ; por el otro, la reflexión metadiscursiva y metaliteraria, donde el francés y su literatura sirven como contrapeso

en la evaluación de otras producciones y otras lenguas, en particular del castellano.

Porque si el francés es para Borges « rather ugly » en los setenta, en los años veinte es uno de los puntos de articulación de su reflexión sobre la lengua.

Preguntarse por Borges y el francés lleva en efecto a preguntarse por Borges y el castellano que se habla en la Argentina, en una cultura cuya legendaria francofilia necesariamente exigía una toma de posición respecto de una lengua postulada, desde el proyecto fundador de los Románticos, como modelo de civilización. A su vez, la pregunta por las vías de legitimación de la lengua literaria en la Argentina, a su regreso definitivo de Europa, lo lleva a reevaluar el lugar que el francés ocupa en la discusión sobre el idioma vernáculo, discusión que viene agitándose desde la perturbadora aparición del libro de Luciano Abeille (1900) en el Buenos Aires de fin de siglo, y que relanza, a principios de los años veinte, Arturo Costa

Álvarez con

Nuestra lengua

(1922). En ambos casos -pregunta por la lengua literaria, pregunta por la lengua de los argentinos- el idioma francés es, en el discurso de Borges, un punto de comparación que nunca queda afuera de la reflexión sobre la lengua, aunque a menudo sea rechazado. A esto se añade la significativa y no tan pequeña circunstancia de los años de formación en Europa : ese mismo idioma francés, excluido como modelo de lengua para un idioma de los argentinos en los años veinte y satíricamente entregado a Victoria Ocampo en los años treinta, había sido abrazado con notable fervor en la juvenilia del Collège Calvin y en el

inicio de la vida literaria en Europa : en 1919 se jactaba por ejemplo Borges, en carta a Abramowicz, de sus « gallicismes, aussi fréquents dans ma prose espagnole que le sont les hispanismes dans mon français » $(1999: 65)$.

En este marco de análisis, que se centra principalmente en las producciones de los años veinte y treinta, nuestro trabajo busca reconsiderar los términos de una relación con el idioma que parece presentar mayores complejidades que la mera francofobia.

\section{Galiparlantes, arrabaleros, puristas}

La relación de Borges con el francés a partir del regreso definitivo de Europa y su instalación en Buenos Aires, en 1924, se inscribe tangencialmente en la llamada querella de la lengua en la Argentina

4. En los ensayos que componenEl tamaño de mi esperanza

(1926), así como en un conjunto de artículos, encuestas y conferencias que cristalizarán luego en « El idioma de los argentinos 
${ }^{5} »$

(1928), Borges neutraliza el poder simbólico del francés de forma sutil, en el margen de la polémica que opone las tendencias hispanófilas y puristas a la tesis de un hipotético idioma vernáculo, específico de la Argentina, cuya encarnación más inmediata según Borges sería la jerga arrabalera o lunfardo. Para apreciar la sigilosa eficacia de esta operación, conviene quizá detenerse antes en los sucesivos lugares que ocupó el francés en la polémica sobre la naturaleza del idioma hablado en la Argentina -lugares que Borges, por su formación y sus lecturas, en particular la de Arturo Costa Álvarez, ciertamente conocía.

El deseo explícito de una presencia del francés en el castellano de Argentina pertenece a etapas identificables, con hitos históricos y textuales de distinto calibre, que trazan una imaginaria línea de continuidad entre el proyecto de emancipación lingüístico-cultural de la Generación del 37 y el controvertido ensayo publicado por Luciano Abeille en París, en

el año 1900,

Idioma nacional de los argentinos

- Para Borges (para la historiografía común), el lugar del francés en la Argentina tiene que ver de manera evidente, casi escolar, con los procesos de independencia americana y con

el espacio simbólico que Francia ocupa en el programa de liberación lingüística de los románticos, en particular de Alberdi

${ }^{6}$ :

En el Congreso de Tucumán resolvimos dejar de ser españoles ; nuestro deber era fundar, como los Estados Unidos, una tradición que fuera distinta. Buscarla en el mismo país del que nos habíamos desligado hubiera sido un evidente contrasentido ; buscarla en una imaginaria cultura indígena

hubiera sido no menos imposible que absurdo. Optamos, como era fatal, por Europa y, particularmente, por Francia (el mismo Poe, que era americano, llegó a nosotros por Baudelaire y Mallarmé). (Borges $1975: 13$ )

La « resolución » de dejar de ser españoles a través de los franceses resonaba ya irónica en 8 las páginas de

Nuestra lengua(1922),el conocido ensayo del lingüista autodidacta Arturo Costa Álvarez ${ }^{8}$ , en cuya autoridad Borges se apoya para ilustrar sus escritos de la década del veinte ${ }^{9}$ y de quien recoge, por lo demás, numerosos argumentos ${ }^{10}$

. Costa, en el primer capítulo de su ensayo (« Los idiomólogos ${ }^{11}$

»), cita, pues, los siguientes fragmentos tomados de « Emancipación de la lengua » de Alberdi :

La revolución en la lengua que habla nuestro país es una faz nueva de la revolución social de 1810, que la sigue por una lógica indestructible [...]

En su forma actual, la francesa es una lengua de la mayor perfección filosófica[...] Aproximarnos a esta forma por las imitaciones francesas es acercarse a la

[...] perfección de nuestra lengua

Imitar una lengua perfecta es imitar un pensamiento perfecto, es adquirir lógica, orden, claridad, laconismo ; es perfeccionar nuestro pensamiento mismo. Tal es lo que a nuestro ver sucede con nuestras imitaciones francesas. (32-33)

« Endriago de cuerpo castellano con miembros de francés» :

la caracterización que a renglón seguido hace Costa

del proyecto de Alberdi es lapidaria. Llevado por su propia fuerza polémica, ni siquiera contempla 
los ideologemas del mito de la lengua francesa (« lógica, orden, claridad, laconismo

») que introducen, en un discurso sobre la emancipación de la lengua, nuevas formas de imperialismo cultural

.Con mayor urgencia, entiende, debe identificarse el origen histórico de aquel « ideal

argentino"

que hasta hoy persiste con propuestas de una lengua « erizada de inútiles galicismos » :

En [el artículo] hace su autor principalmente una declamación patriotera : un ejercicio retórico sobre asunto supuesto ; y de él resulta, en definitiva, que la supuesta lengua argentina sería simplemente un castellano erizado de inútiles galicismos. [...] Como se ve, es enteramente alberdiano, en cuanto a su origen como ideal argentino, ese endriago de cuerpo castellano con miembros de francés, engendrado por el joven pensador, en un arrebato de pasión patriótica, en el seno de la Furia antiespañolista. (1922 : 33-34)

Aunque en rigor de verdad, como lo demuestran las muchas páginas deNuestra lengua

que le son dedicadas, el verdadero espantapájaros de Costa Álvarez, en lo que al castellano galicado refiere, no es Alberdi (que por otra parte Costa intenta recuperar para su causa sosteniendo que, al igual que Echeverría, Gutiérrez y Sarmiento, ha sido «tergiversado

$\left.{ }^{13} \gg\right)$, sino Lucien Abeille, autor de un libro que aparece con el siglo :

Idioma nacional de los argentinos(1900).

Inmigrante francés instalado en la Argentina desde 1890, protegido de Carlos Pellegrini y entroncado familiarmente con la oligarquía porteña, Luciano (o Lucien) Abeille se presenta como un enamorado de la argentinidad en ciernes. La tesis central de su libro, en consonancia con las ideas evolucionistas de Renan y de Humboldt, es que la autonomía lingüística debe acompañar la autonomía política. Más aun, como observa Gerardo Oviedo (2005 : 15), Abeille une causalmente ambos fenómenos al considerarque la« fuerza revolucionaria histórico-evolutiva de origen políticoes la potencia creadora que recorre los nervios del habla de los argentinos »

. La vocación de un idioma propio, consustancial con la autonomía política, provocará la evolución (sintáctica, léxica, fonética) del idioma, hasta un futuro y definitivo apartamiento del español como lengua hegemónica y la llegada de un « idioma nacional de los argentinos »

. Entretanto, ciertos factores externos, que Abeille se propone estudiar científicamente ${ }^{14}$ , van apresurando el cambio : el primero de ellos es la inmigración o«

cruzamiento, en una nación perfectamente homogénea, [de] las diversas razas que se establecen en su seno

》(138). De esta manera se fomenta el« contagio de lenguas »

(139) y la consecuente aparición de neologismos. Un caso específico de ese contagio es el francés, cuya

« influencia sobre la sintaxis argentina »

(la idea es desarrollada en el capítulo IX) es deseable, en tanto provoca « construcciones que se alejan del mecanismo sintáctico español "y favorece positivamente «la evolución del argentino»

. Para el profesor de francés del Colegio Nacional Buenos Aires, ese proceso de mezcla es « el esplendor y el prestigio de la literatura francesa » : así» anhelado, entre otros motivos, por 
como Horacio, Virgilio, Cicerón no han podido sustraerse a la influencia de la lengua

griega

"(328), tampoco los escritores argentinos logran evitar"

en su sintaxis los efectos de la influencia francesa" que al ser «

esencialmente clara, satisface la necesidad imperiosa de claridad que es uno de los rasgos característicos del carácter argentino

$15 »(334)$.

De más está decir que el ensayo, que profetizaba la disolución del castellano y buscaba (en palabras de Costa Álvarez) demostrar « que los argentinos tenemos un idioma privativo, o

${ }^{16} »\left(1924\right.$ : 113), recogió una caterva de enconadas respuestas ${ }^{17}$

un principio de tal ganga

, la más famosa siendo quizá la de Paul Groussac, a quien Borges cita en « El idioma de los argentinos » (1928 : 227) y de quien dirá, ochenta años más tarde, que « fustigó a Luciano

Abeille, que postulaba un idioma argentino » $(1981: 196)$ :

[...] queda siempre de pie un hecho indestructible, y es que el castellano existe. [...] Quitado ese, ¿con qué se le reemplaza ? ¿Se rechazará la carabela en nombre de la jangada? Se declara caduco el idioma de Quevedo, para sustituido ¿con qué ?, ¿con el de Goethe, o Macaulay o Renan ? No : por el mismo castellano, tal cual lo hablan allá los que no saben hablar, y salpimentado de unos cuantos modismos tan genuinamente «criollos », que no se oye otra cosa en las esquinas de Triana y los malecones de Cádiz. No existe tal « idioma argentino » en formación ; ni tendría importancia, aunque fuera más original y completo, cualquier patuá rústico que aquí coexistiese con la lengua culta, como ocurre en todas las provincias de Europa.

(Groussac, 1900 : 414)

Desde un punto de vista retórico, las descalificaciones a las tesis de Abeille responden, en general, a un mismo procedimiento argumental que nivela el « idioma argentino » con el

ocuciones bárbaras de la gente rústica o [con] la jerigonza cosmopolita de algún barrio suburbano $18 \gg$

(la descripción pertenece a Juan B. Terán) ; dichas locuciones -se sostiene- o derivan del propio acervo popular español, o son deformaciones que conviene controlar desde el aparato educacional del Estado.

《

Repudio un libro como el del Dr. Luciano Abeille, escribe Rojas, porque carece de sistema científico y porque fomenta las inclinaciones más barbarizantes y vanas del patrioterismo

criollo $19 »$.

Hasta aquí, las críticas en contra de las ideas ; será un compatriota del lingüista francés (nacido, como él, en Toulouse) quien aseste el golpe ad hominem

. En una nota al pie donde ni siquiera se rebaja a escribir su nombre, Paul Groussac le reprocha a Lucien Abeille su mal castellano:

No merece mención una rapsodia reciente, en que la ignorancia absoluta del asunto, comenzando por el castellano, toma la forma de una baja adulación al criollismo

argentino

»(1900 : 37). A partir de esta inicial desautorización hecha por un francés quesí entiende de castellano, Costa Álvarez va un paso más allá y mezcla, 
en una operación que él lee como un bastardeo, al francés con las restantes variantes del

»descriptas por Abeille. Aparece en efecto, a lo largo deNuestra lengua,

« argentino

la idea recurrente según la cual la pátina francesa,otrora lengua de« civilización »

(Molloy $1972: 15$ ) y de transmisión de saber,

es ahora invocada para dar un lustre de finura y legitimidad al « bodrio » de la eventual lengua privativa de los argentinos :

Surgen, pues, los idiomólogos, los encargados de componer la lengua artificial que debemos hablar los argentinos patriotas. El plan adoptado es cambiar de léxico y de sintaxis : el vocabulario será gauchesco, la construcción será francesa, y del castellano no quedará sino lo indispensable para que el aparato no se venga abajo.

Al enterarse de este plan, los escritores barbáricos ofrecen solícitamente sus servicios. También se los recibe cordialmente : su lengua antigramatical y afrancesada promete hacer de ellos muy valiosos auxiliares. (1922: 91)

Con el lenguaje gauchesco, el lunfardo presidiario, el guirigay arrabalero, las jergas gringocriollas, un puñado de vocablos guaraníes, quichuas y araucanos, el inglés para los deportes y el francés para las modas, todo ello ligado en concordancias falsas o truncas, o por preposiciones elegidas al azar, y presentado en giros cuidadosamente galicados a efectos de dar vista, aroma y sabor de néctar al bodrio, hay ya ingredientes de sobra para cocinar el idioma argentino (1922: 100).

[...] favorecer en la lengua escrita el barbarismo y el solecismo, especialmente los de sello galicado, hasta que uno y otro vicio prevalezcan sobre toda forma de

expresión castiza. Mal patriota será el que no hable a lo gaucho, a lo compadrito o a

lo gringo, el que no escriba a la francesa o a la diabla (1922:128).

La nacionalidad y la prosa efectivamente galicada de Abeille desacreditan de este modo « lengua antigramatical y afrancesada de los escritores barbáricos »,« mal patriota el que noescribaa la francesa o a la diabla »

. Es decir : las marcas sintácticas y léxicas de una lengua prestigiosa, culturalmente

legitimadora como el francés, se vuelven signo, en el ensayo de Costa Álvarez, de la « contaminación "y la« corrupción »

del habla popular. La maniobra es hábil y permite descartar, sin atacarlos de frente, el entusiasmo y la fe en la lengua francesade los prohombres del XIX.

Hay que observar, por lo demás, que el fuerte rechazo a las tesis de Abeille tiene que ver con la Argentina de fin de siglo. Cuando « la bomba lingüística ${ }^{20}$ »que es su libro estalla en el 1900,

el debate sobre la lengua es la caja de resonancias de coyunturas políticas y sociales altamente conflictivas, tanto en el frente interno como en el externo. En el frente interno, tal como lo ha estudiado la crítica

21

, la élite intelectual responde al fenómeno de la inmigración y a sus amenazas babélicas con un repliegue identitario que devuelve la norma lingüística a la preceptiva purista e

hispanizante. En el frente externo, a su vez, las políticas expansionistas de los Estados Unidos empujan a buscar modelos culturales no sajones, que por cierto ya se encuentran en la incipiente defensa nacionalista de la hispanidad 22.

Es interesante, a la luz de este denso contexto polémico, leer los ensayos sobre la lengua

El tamaño de mi esperanzay « El idioma de los argentinos » 
. Por ejemplo el principio de «El idioma infinito »

, texto inicialmente publicado en el diarioLa Prensa, enjunio de 1926 :

Dos conductas de idioma (igualmente tilingas e inhábiles) se dan en esta tierra.

Una, la de los haraganes galicistas que a la rutina castellana quieren anteponer otra rutina y que solicitan para ello una libertad que apenas ejercen; otra, la de los casticistas, que creen en la Academia como quien cree en la Santa Federación y a cuyo juicio ya es perfecto el lenguaje (Esto es, ya está todo pensado y ojalá fuera así)

$(1926: 35)$.

El plural de los « haraganes galicistas » naturalmente remite al « doctor don Luciano Abeille » $(1926$ : 106) y a sus seguidores, aunque también, de manera indirecta, al proyecto romántico de importación del modelo francés. Esa

importación, pasiva en tanto préstamo y voluntarista en tanto proyecto, es según Borges, hoy, en la década del veinte, una afectación ; a lo sumo (como escribirá luego en la polémica sobre el meridiano intelectual) una obsesión española que únicamente se observa en Madrid, « ciudad cuya sola invención es el galicismo -a lo menos, en ninguna otra parte hablan tanto de él $23 \gg$

. De alguna manera, sin embargo, el proyecto de los hombres del 37 reaparece en la propuesta central de « El idioma infinito »: « instigar una política del idioma »

que al renovar la lengua, renueve las representaciones. No era otro, como bien se sabe, el programa de raigambre ilustrada que planteaban los románticos : una renovación de la lengua que acompañara eficazmente la renovación de las ideas 24

. Totalmente risible, a la luz de esta ambición, le parece a Borges la disputa entre puristas hispanófilos y galicistas abeillescos : la controversia sobre si se dice ocuparse deuocuparse con, anota, sólo produce« ruiditos » y carece« d e toda eficacia ideológica ».

Igualmente absurda le resulta la posibilidad de un idioma autóctono, surgido del fenómeno de la inmigración. Borges sigue en esto los argumentos de Costa Álvarez (que a su vez sigue a Groussac y a Cané), aunque identificando con más fuerza las « locuciones bárbaras » producidas por la heteroglosia, con el lunfardo arrabalero. Esa identificación ya había sido desarrollada en la « Invectiva contra el arrabalero » (1926), donde el lunfardo, « vocabulario gremial », era una chata « afectación » que de ningún modo podía fundar « ese chúcaro idioma nacional que hace veinticinco » el Doctor Don Luciano Abeille »(1926: 106): años nos recomendó y prescribió

Desertar porque sí de la casi universalidad del idioma, para esconderse en un dialecto chúcaro y receloso -jerga aclimatada en la infamia, jerigonza carcelaria y conventillera que nos convertiría en hipócritas al revés, en hipócritas de la malvivencia y de la ruindad- es proyecto de malhumorados y rezongones. Ese programa de trágica pequeñez fue declinado ya por De Vedia, por Miguel Cané, por Quesada, por Costa Álvarez, por Groussac.

¿Se rechazará la carabela en nombre de la jangada?,

hizo como que preguntaba este último, con ejercitada ironía. (1928 : 227) 
Ahora bien, $u$

n mismo desprecio ostenta Borges por el contrincante opuesto, el casticista que se subordina al poder del diccionario de la Real Academia española. El argumento según el cual no es posible un aporte argentino a la lengua castellana porque ésta ya ofrece un enorme caudal de palabras es, según Borges, « de haragana inmovilidad » (1926a : 40) : el hablante se vuelve entonces« patán » o« jayán » -a la pereza mental la acompaña la torpeza física- embobado por una riqueza ilusoria

25

. Una y otra vez vuelve esta idea en los ensayos sobre la lengua de los años veinte. La « nuestro diccionario, el de los españoles » $(1928: 227)$ riqueza de es debida, entre otros motivos, a la inclusión en sus páginas de múltiples voces en desuso que convierten al diccionario en« desfile verbal de fantasmas o de ausentes o de difuntos » (1928 : 228-9).

El argumento, que toma de Costa Álvarez ${ }^{26}$

, le permite desarmar el « criterio acumulativo que sigue cargando sobre el léxico de la Academia los vocabularios enteros de germanía, de heráldica, de arcaísmos »(1928: 228)

. En cuanto al uso (literario) de esa supuesta riqueza léxica, difícilmente pueda hablarse de valor estético : lo que hay, sostiene, es un abuso de la sinonimia. Y esos sinónimos, que ni multiplican las representaciones, ni ayudan« a sentir [o] pensar » (1925a : 36) sólo sirven, en literatura, para« e vitar alguna asonancia y lograrle música a la oración” (1925a : 36), según la (flaubertiana) « C oncepción acústica del estilo » que al no poder cambiar de idea, cambia de ruido (descalificación macedoniana si las hay 27).

Pero tomar esa irremediable pobreza de representaciones, « esa retahíla baratísima de sinónimos por arte literario, es suponer que alguien es un gran matemático, porque primero escribió tresy al ratoIIly, finalmente, raíz cuadrada de nueve »(1926b : 47).Así se arman « los arreos, galas y riquezas del español, por otro nombre el fraude » (1928 : 229), siempre acompañado por sus consabidos defensores americanos, que a su vez cuentan, como señala Di Tullio (2013: 72), « co n una genealogía y un estilo(Capdevila : "Viva Dios, pronta está la merienda ") ».

Como puede verse, el descreimiento de Borges respecto de los posibles modelos de afinamiento del castellano hablado en la Argentina engloba por igual a los defensores de una lengua privativa, a los importadores de xenismos y pautas francesas, a los defensores del purismo castizo. Por cierto, esta triple asociación ya la había hecho « el doctor

", que en su discurso inaugural del Instituto de Filología, en 1923, tres años antes de El tamaño de mi esperanza

, había definido los mismos contramodelos : « Ni arrabaleros o galiparlantes, ni fetichistas del incompleto diccionario de la Academia Española

$28 »$.Borges reduce las tres tendencias a $\operatorname{dos}^{29}$ 
, desplazando así la línea francesa (que sin embargo, como veremos, se cuela por otra parte). $Y$ ante la pregunta sobre cómo hacer nuestro

el español sin perder la universalidad que confiere su uso, ofrece una respuesta ética : la de un deber del escritor que es insuflar, en el interior mismo del castellano, un idioma que proyecte una sensibilidad argentina. «El problema verbal (que es el literario, también)

》(1928 : 234) convoca en efecto el deber « nuestro y de todos "

(1925a : 38), el « deber de cada uno [...] y el de los escritores, más que nadie »

(1928: 234), de « multiplicar y variar »

la lengua. De esta forma la respuesta inicialmente comunitaria es progresivamente modalizada por lo estético, en un recorrido que se revela en cambios paratextuales, por ejemplo la modificación del inicial y genérico título « Acerca del vocabulario "al más específico « Palabrería para versos »

, o en excursos significativos, como el que le dedica en « El idioma de los argentinos » a John Wilkins, « el más inteligente utopista en trances de idioma que pensó nunca »

(1928 : 228). En este sentido se superponen dos problemáticas, que Borges entrelaza intencionalmente : la de un idioma exclusivo de los argentinos, la de un idioma exclusivo de la literatura ${ }^{30}$.

\section{Conquistar nuestra pobreza}

En un muy temprano artículo sobre «Borges y el lenguaje »

, de 1953, Ana María Barrenechea vincula la lengua en Borges con el orden de los afectos:

« un manejo natural del lenguaje, no entorpecido por la timidez, que Borges cree característica de los argentinos y que, en el caso del habla, se agrava por la idea de estar utilizando un idioma que es como prestado o ajeno

(1953 : 556). Esa afectividad reaparece en el diagnóstico de la situación del castellano en la indigencia, pobrezayausteridad Argentina, que Borges modula en torno a las nociones de , nociones que a su vez convocan en su prosa afectos de pertenencia nacional :

Sabemos bien las vergüenzas de nuestro idioma [...] hemos padecido en pobreza propia lo balbuciente que es. [...] Pero nosotros quisiéramos un español dócil y venturoso, que se llevara bien con la apasionada condición de nuestros ponientes y con la infinitud de dulzura de nuestros barrios y con el poderío de nuestros veranos y nuestras lluvias y con nuestra pública fe. $(1928: 235)$

Cómo remediar la distancia entre « nuestra realidá vital grandiosa »

$\mathrm{y}$ « nuestra realidá pensada mendiga »

(1926 : 15), qué hacer cuando uno quiere escribir en castellano desde la Argentina : las preguntas en esos años giran en torno a la supuesta pobreza del español de América, aquello que Guillermo de Torre llamaría más tarde, hablando de los sufrimientos lingüísticos de la joven Victoria Ocampo, « el empobrecido castellano vernacular del medio $»(1951: 110)$ 
Antes de exponer los planteos de Borges sobre lo que aún, en la década del veinte,

$$
31 \text { »del idioma nacional, es importante notar que en el interior mismo de }
$$

El tamaño de mi esperanza

conviven distintas capas de propuestas respecto de la lengua y la tarea del escritor, que luego cuajan en « El idioma de los argentinos

》

. Esto sucede porque el libro está compuesto por artículos previamente publicados en la

revista

Proay en el diarioLa Prensa. Cinco son los ensayos que, enEl tamaño de mi esperanza,

se ocupan específicamente del lenguaje : « El idioma infinito »

(julio 1925), « Palabrería para versos »(2 de mayo de 1926), « La adjetivación »

(16 de mayo 1926), « Invectiva contra el arrabalero »

(6 de junio 1926), «Profesión de fe literaria »

(27 de junio 1926). Los textos a su vez dialogan con los primeros prólogos de

Fervor de Buenos y Airesy deLuna de enfrente :« A quien leyere »(1923) y « Al tal vez lector »

(noviembre 1925). Si bien todos estos ensayos tienen en común el intento de obligar al español a « salir de su casa

$\gg$

(1928 : 166), una lectura que tenga en cuenta el tiempo que hay entre ellos muestra las (rapidísimas) variaciones y desplazamientos del pensamiento de Borges ante el problema de la lengua.

Las propuestas de intervención pueden quizá sintetizarse en dos momentos, en dos carriles de ideas que en realidad conviven y se superponen en los ensayos. El primero es conceptual y « utópico

》

(1926a : 43), y responde a las propias inquisiciones borgeanas sobre la filosofía del lenguaje y a su no tan lejano comercio con las propuestas de innovación de la vanguardia ultraísta. El segundo incluye, de forma más literal y concreta, una afectividad, un contexto histórico y una pertenencia de clase que reenvían al modelo de escritura que Elvira Arnoux y Roberto Bein supieron llamar « coloquialismo culto

》)

(1997 : 19). En ambas propuestas, el francés es intencionalmente desplazado como modelo de lengua.

La política conceptual y utópica de ensanchamiento del idioma expuesta en « El idioma infinito" (1925a) y en « Palabrería para versos

»(1926a) es la respuesta de un argentino, a la sazón escritor, a la « sedicente riqueza » del diccionario español. Para ello propone Borges « instigar una política del idioma » (1925a : 35) que no pase ya por la multiplicación de las voces (more

diccionario), sino por la multiplicación de las representaciones, fenómeno justamente posible porque la lengua « es edificadora de realidades "(1926a : 41) y porque « los sustantivos, se los inventamos a la realidad "

(1926a : 40). Ahora bien, en la medida en que el valor resulta de la novedad de la representación (y no ya del número de signos), son falaces tanto el caudal del español, que se agota en la sinonimia (« la representación no [cambia], cambian los signos 
»-1926b : 47), como la «pluralidad verbal o indigencia conceptual »

(1926c : 106) del arrabalero o lunfardo : distintas caras de una misma pobreza de pensamiento.

En esta tesitura el escritor, que en su calidad de inventor puede concebir « un vocabulario deliberadamente poético, registrador de representaciones no llevaderas para el habla

(1926a : 42), adquiere un rol central en la renovación y enriquecimiento de la lengua. De allí el planteo teórico de programas y esquemas semánticos utópicos :

¿Por qué no inventar [una palabra] para el ruinoso y amenazador ademán que muestran en la madrugada las calles? ¿Y otra para la buena voluntad, conmovedora de puro ineficaz, del primer farol en el atardecer aún claro ? ¿Y otra para la inconfidencia con nosotros mismos después de una vileza? (1926a : 43)

De allí también la propuesta, en " El idioma infinito », de diversos procedimientos ${ }^{32}$

de renovación de la lengua : derivaciones innovadoras a partir de voces ya existentes (y no a partir de préstamos de otras lenguas : en esto, Borges sigue tácitamente oponiéndose a las tesis de Abeille y a la entrada de voces extranjeras en la lengua 33

); combinaciones morfológicas nuevas con preposiciones fijas, como lo hace el alemán ; usos etimológicos de las palabras, como lo hicieron los clásicos « y singularmente algunos

ingleses

》

(1925a : 37). Cabe notar que estas propuestas de innovación excluyen sistemáticamente el francés como potencial modelo morfológico derivativo, a diferencia del alemán o del inglés, centralmente mencionados. El francés, como el castellano, le resultará siempre a

Borges un idioma poco flexible, y el reproche que le hará tiempo después a su lengua materna -el castellano y su « ineptitud para formar palabras compuestas

([1941] 1996 : 33) - se lo endilgará por igual, y para la misma época, al francés, siguiendo un tópico clásico de la crítica al idioma de Voltaire : la inflexibilidad morfológica (Philippe y Piat 2009 : 7-15). Así, en el « Fragmento sobre Joyce ", breve nota sobre la invención verbal en elUlysses

, cita Borges, deslumbrado, la serie de sustantivos compuestos que describen la cama de la

Bridebed, childbed, bed of death, ghostcandled madre de Stephen Dedalus :

. Y en una nota al pie, que en el fondo es gratuita en relación al tema del ensayo, apunta destempladamente : « La versión francesa no es muy feliz :

Lit nupcial, lit de parturition, lit de mort aux spectrales bougies.

La culpa es del idioma, naturalmente, incapaz de voces compuestas ${ }^{34}$ »[1941] $\left.1996: 169\right)$.

Innovaciones léxicas, « ideaciones »semánticas que se dedican « al gran Xul-Solar »

(1925a : 38) y que encuentran filiación en las lenguas germánicas o sajonas : son, éstas, aproximaciones teóricas para una práctica que en realidad ya viene sucediendo. Pues como señala Rafael Olea Franco (1993 : 182),

Luna de enfrente

ya encarnaba el « notorio deseo de realizar innovaciones lingüísticas en distintos estratos 35 
». Como puede verse, la pregunta por la especificidad de la lengua se superpone con el ímpetu vanguardista, inventor de procedimientos, y se desplaza hacia la invención de un idiolecto y hacia un juego con la lengua propiamente literarios. Bien lo observa Costa

Álvarez, que en el capítulo que le dedica a Borges en

El castellano en la Argentina(1928) habla de un « dialectismo individual ininteligible » provocado por « una necesidad personal », de «

letras raras [que] caerán como gotas de tinta en el mar del castellano usual »(1928: 96) :

Un conocimiento bastante de otros idiomas le ha revelado que el castellano carece de algunos recursos expresivos, no obstante sus cuantiosas sinonimias ; y quiere crear esos recursos sin cuidarse, y así me gusta, de que sus letras raras caerán como gotas de tinta en el mar del castellano usual. Los gramáticos lo llamarán neólogo ; la cultura ve en él un ideólogo para el cual la lengua no debe tener formas rígidas sino flexibles, y adaptables a todas las presiones del sentir y del pensar; por lo que proclama y ejerce la libertad de derivar, de componer, de reformar palabras, de hacerles trasvasar las casillas gramaticales, de retrotraer su significado actual borroso al clarísimo originario... Bien, muy bien ; aplaudo una actitud tan resuelta, impuesta por una necesidad personal tan imperiosa ; y lo aplaudo sin reservas porque no temo que el ejemplo cunda, y que nuestra lengua caiga en un dialectismo individual ininteligible. El arte de innovar no es don de todos : [...] y esto basta para que nos vuelva el alma al cuerpo a los que queremos que la lengua sea un medio de universal inteligencia. (1928: 96)

Costa, sin duda conmovido por el aval y la legitimación que le conferían las citas que de él

, en cierto punto se apropia de la figura del promisorio escritor al dedicarle un capítulo de su ensayo de 1928, elocuentemente llamado « Albores de argentinismo

»

. Borges le devolverá el cumplido años más tarde, en una nota al pie de « Las alarmas del doctor Américo Castro

", donde defineEl castellano en la Argentinacomo « un libro esencial »

([1941] 1996 : 32), tomando definitivamente partido por el díscolo rival de los filólogos del Instituto.

Hay que señalar, por lo demás, que la propia evolución del joven Borges respecto del castellano derivaría gradualmente hacia las templadas posturas de Costa Álvarez, como lo observó de hecho el platense (1928: 30) en la síntesis que hace de

El tamaño de mi esperanzaen el principio deEl castellano en la Argentina :

El autor afirma que los argentinos no tienen más idioma que el castellano al que aplican una sensibilidad que, por ser argentina, no es la de otros pueblos a pesar de

la comunidad de lengua ; y de ahí que entre el castellano nuestro y el ajeno, el español sobre todo, haya diferencias en la afición o aversión a determinados vocablos o giros [...] $(1928: 30)$

Esta segunda valoración del ensayo de Borges por parte de Costa Álvarez remite al otro carril de ideas sobre la lengua que se expresan en

El tamaño de mi esperanzay se fijan en «El idioma de los argentinos »

: el de la afectividad, la pertenencia nacional y la pertenencia de clase, que traducen « la voluntad política de construir discursivamente una identidad nacional y un lenguaje propios

(Arnoux y Bein 1997 : 22) y configuran la « materia donde pueden inscribirse las huellas de una sensibilidad y una nación 
(Sarlo 1988 : 118) -una sensibilidad y una nación que a su vez se identifican, hay que observarlo, con la oralidad patricia de la clase alta. Dejando a un lado la potencialidad de la innovación léxica, Borges propone para el español de « nuestra conversación argentina $\gg$

« un matiz de diferenciación lo bastante discreto para no entorpecer la circulación total del idioma y lo bastante nítido para que en él oigamos la patria »(1928: 232) :

No hemos variado el sentido intrínseco de las palabras, pero sí su connotación. Esa divergencia, nula en la prosa argumentativa o en la didáctica, es grande en lo que mira a las emociones. Nuestra discusión será hispana, pero nuestro verso, nuestro humorismo, ya son de aquí. Lo emotivo -desolador o alegrador- es asunto de ellas y lo rige la atmósfera de las palabras, no su significado. (1928: 233)

El matiz idiomático diferencial del castellano de la Argentina pasa por un tono, una coloratura, un afecto, no asumidos del todo y que sin embargo logran oponerse a la hispánica« variedad de palabras » (1926d : 116) y a las« farolerías » del« compadrito de la esquina » (1925a: 36). El

ensanchamiento del castellano que se habla en la Argentina presupone así la constatación de su estado potencial, de su futuro, a la vez que afirma su actual, supuesta pobreza

léxica. « Supuesta ", primero, porqueen su« Profesión de fe literaria », Borges hace de la pobreza, un valor :

Que nadie se anime a escribirsuburbio

sin haber caminoteado largamente por sus veredas altas [...] sin haber sentido sus tapias, sus campitos, sus lunas a la vuelta de un almacén, como una generosidad... Yo he conquistado ya mi pobreza ; yo he reconocido, entre miles, las nueve o diez palabras que se llevan bien con mi corazón. (1926d : 116)

Y porque además, como lo desarrolla en «El idioma de los argentinos »

, hay lenguas que transforman la pobreza en austeridad. Y el modelo en este caso es, naturalmente, el francés : « la cortedad léxica [del francés] es economía y ha sido estimulada por sus retóricos. Servicial o no, el vocabulario chico de Racine es deliberado.

Es austeridad, no indigencia »(1928 : 231).Así, pues, como escribeacudiendo una vez más a Costa Álvarez ${ }^{37}$, el francés prueba que el criterio cuantitativo no es criterio de calidad, y que

la riqueza de una lengua depende no del número sino del uso, que multiplica (o no) las visiones de mundo. Mayor diferencia puede haber en el habla de dos franceses o de dos españoles o de dos argentinos, que en la comparación entre dos idiomas :

Arturo Costa Álvarez (Nuestra lengua , página 293) narra el procedimiento simplista usado (o abusado) por el Conde de Casa Valencia para cotejar el francés con el castellano. Acudió a las matemáticas el tal señor, y averiguó que las palabras registradas por el diccionario de la Academia Española eran casi sesenta mil y que las del correspondiente diccionario francés eran treinta y un mil solamente. ¿Quiere decir acaso este censo que un hablista hispánico tiene 29.000 representaciones más que un francés ? (1926a : 39-40) 38 .

Significativamente, la pobreza léxica como cualidad remite al modelo clásico de austeridad de la lengua francesa y contrasta con los « haraganes galicistas "americanos que « a la rutina castellana quieren anteponer otra rutina » 
(1925a : 35). De esta manera se dibuja, por un lado, la idea en abstracto, positiva, del francés austero como lengua clásica y por el otro, el francés que es mezcla con otras lenguas, préstamo, marca de inestabilidad del castellano. Entre esas dos valoraciones oscila Borges : entre el francés de Racine y el de Abeille y la chusma. Es, en definitiva, la distancia que separa al galicismo de las figuras de « Groussac y Reyes [que] le enseñaron a simplificar el vocabulario, entorpecido entonces de curiosas fealdades

»(1974: 1143) :

Groussac juzgaba que el francés, a lo largo de las generaciones, ha sido más trabajado que el castellano y que debía ser su modelo, así como lo fue el latín, en el siglo XVII, para Quevedo y para Saavedra Fajardo. Esto no significa que aprobara o aconsejara los galicismos, pero sí la economía verbal y la probidad que son características del francés. (1981: 27)

Esta economía verbal y probidad características del francés no serán sin embargo invocadas por Borges en su propuesta de un castellano fundado en la cálida conversación porteña de « nuestros mayores »(1928 : 231), aun cuando el francés es tradicionalmente parte de esa conversación o causerie

: la lengua francesa como « guiño al lector (de la misma clase y cultura que el escritor)» , « código cifrado para los pares »

(Olea Franco 1993 : 191), signo de un « cosmopolitismo legítimo » que se enfrenta al « cosmopolitismo babélico »

de la ciudad de la inmigración (Sarlo 1996 : 4). Ahora bien, aunque Borges propone un modelo de lengua instaurado en la oralidad patricia

, en ninguna de las descripciones que hace de ese « no escrito idioma argentino [que] sigue diciéndonos" menciona al francés. 0 más bien : lo menciona negándolo. « La heterogénea lengua vernácula de charla porteña »(1925b : 219) que debe fundar, sin extranjerismos de « recién venidos ${ }^{40}$ »

(1928 : 232), la « plena entonación argentina del castellano»

tampoco ha de contener "fervor »alguno (y el sustantivo pesa en su poética) « a lo francés 》"

: « pasar inadvertidos, hacernos perdonar esa guarangada del tango, descreer de todos los fervores a lo francés y no entusiasmarse, es opinión de muchos »(1928 : 232). Así describe Borges una de las formas actuales del « ser argentino » , que oportunamente coincide con las ideas propias, y no tanto con la práctica de los « mayores 》.

El gesto puede sorprender en una sociedad como la argentina de las primeras décadas del siglo XX, donde el francés es, justamente, como en tantos otros lugares del mundo, marca de prestigio y de pertenencia en letrados y clases altas. Más aun, la voluntariosa escisión entre oralidad y lengua francesa es propuesta por un escritor que pertenece a la oligarquía y que naturalmente conoce los códigos de roce y trato que incluyen el francés, como puede por ejemplo verse en este diálogo con Victoria Ocampo donde Borges, fiel a su costumbre en el registro oral, rápidamente se adapta al idiolecto del interlocutor : 
JLB : Sí, yo siempre supe, de algún modo, que sería un escritor. En cuanto a mis ambiciones, no sé si le he dicho alguna vez, Victoria, que cuando era chico se hablaba mucho de "ratés" -no se usaba la palabra "fracasados" sino la francesa "ratés"-, yo oía hablar de los "ratés" y me preguntaba con inquietud : "¿llegaré yo alguna vez a ser un "raté" ?" Esa era mi máxima ambición.

VO : Pero usted ha fracasado como "raté". (1969: 37)

¿Cómo explicar entonces tanto recelo ? Un motivo verosímil, muchas veces evocado, es el posicionamiento en el campo intelectual de la época : ir en contra de « todos los fervores

", es ir en contra del galicismo mental de Darío, del « argentinismo francesista »

de Lugones (1997 : 207), del propio fervor simbolista de Güiraldes, de « la afrancesada secta de voces que embolisman la charla, descalabran toda cuartilla

([1925] 2008 : 167-168). Es, además, un gesto que está en línea con otros ejercicios de irreverencia francófobos que Borges leía en esos tiempos, por ejemplo « Nuestros clásicos franceses. Sus incomparables enseñanzas ", antología satírica que cierra Nuestra lenguadonde (en la más pura tradición de losbêtisiers

flaubertianos) Costa arma una antología de errores e inexactitudes científicas cometidas por escritores franceses ${ }^{41}$.

Esta estrategia de diferenciación se radicaliza en la década del treinta, con la aparición en el mundo de Borges de la figura de Victoria Ocampo.

\section{Norah y las moscas, Victoria y los carneros}

El vínculo que Victoria Ocampo establece entre el francés y el castellano se opone esencialmente al recorrido propuesto por Borges. De Ocampo podría banalmente decirse lo que Borges escribió de Carriego : que « era o se sentía una especie de francés honorario "(1963 : 42); del Borges de los años veinte podría haber escrito Ocampo lo que pretendía para sí misma :

« Lo que más me interesa decir es principalmente aquí, en mi tierra, donde tengo que decirlo, y en una lengua familiar a todos »(1931:24).

Lo notable es cómo, a partir de códigos sociales comunes y de diagnósticos finalmente análogos respecto de la situación del castellano en la Argentina y la riqueza del español peninsular, que sienten ajena, ambos arman modos de relación antagónicos con el francés. Las nocionespara pensar la problemática de la lengua son, por lo demás, similares, y remiten al campo de lo económico : indigencia, pobreza, riqueza, importación de un capital simbólico que conlleva deudas, constitución de un capital propio y a partir de qué. Es en la definición y aplicación de estas nociones donde Borges y Ocampo disienten profundamente. 
En lo que al castellano patrio refiere, el diagnóstico es inicialmente el mismo : pobreza, falta de matices, estrechez del vocabulario. Pero allí donde Borges adivina y anhela una austeridad enriquecida por futuros experimentos de innovación vanguardista, por la cercanía de un paisaje o la entonación del afecto, Ocampo ve penuria »

$\ll$ (1931 : 29),« tartamudeo de los pueblos jóvenes »(1950: 40),«

un español empobrecido, impropio para expresar todo matiz » (Ocampo 1931 : 30). Son, estos, dos diagnósticos opuestos ante una misma sensación de escasez. Un ejemplo ilustrativo lo da el adjetivo « lindo » , que los lleva a argumentaciones estrictamente inversas. Apunta Ocampo:

Hacia mis quince años, ningún poder humano me habría hecho emplear los calificativos "bello" o "hermoso"; "lindo" me parecía el único término que no era pedante. (Ocampo $1931: 29$ )

Sostiene por su lado Borges :

Nuestrolindo

es palabra que se juega entera para elogiar; el de los españoles no es aprobativo con tantas ganas. (Borges $1928: 233$ )

La pobreza que en Borges provoca sentimientos de orgulloso entusiasmo por lo propio y magnificación del sentido, despierta en Ocampo una voluntaria parquedad.

Opuestos también, Borges y Ocampo, en la autoridad que eventualmente le reconocen, o no, a España respecto de la tutela del idioma y en la exacta naturaleza de la riqueza del « español de ultramar

(Ocampo 1931 : 30). A diferencia de Borges, que de forma tajante y en más de una ocasión marcó su distancia con España

42

, Ocampo finalmente acepta, en la figura de Ortega y Gasset, un mentor que le revela las riquezas del acervo hispánico

${ }^{43} \mathrm{y}$ que endereza, mal que mal, el inicial desaire hacia la lengua madre :

[...] Sólo en 1916, cuando el primer viaje de Ortega después de haber conversado largamente con él, advertí gradualmente mi tontería. Comenzaba a descubrir que todo podía decirse en lengua española sin por ello volverse automáticamente pesado, afectado, grandilocuente. Pero este descubrimiento llegó demasiado tarde. Hacía ya mucho tiempo que era prisionera del francés. (1931: 30)

Pero antes del descubrimiento, las dificultades de Ocampo con el idioma castellano «

Sabemos bien las vergüenzas de nuestro idioma » 1928 : 234). Nótese que el común recelo con la lengua materna es posible, como señala Sarlo, para

« quien esdemasiado

rico en lenguas, resultado del fluir de la abundancia y no de la pobreza simbólica » (1996 :

8). La biblioteca inglesa de « padre », la educación en Ginebra, 
« Racine et Mademoiselle » (la institutriz que Ocampo evoca en uno de losTestimonios -1941) : tales son las circunstancias que dan margen para la crítica de una lengua que se posee como herencia, y que como tal puede ser rechazada. Lo notable es que la misma dificultad, timidez o parsimonia presentida en el habla materna produce metadiscursos contrarios en ambos escritores : ante la propuesta de Borges de ensanchamiento del idioma, de instigación de una política del idioma, se dibuja en Ocampo una lectura retrospectiva basada en la sustracción.

En el tercer número de la revistaSur

, en 1931, Victoria Ocampo publica en efecto un texto apologético,"

Palabras francesas », donde narra su relación simbiótica, iniciática, con la lengua francesa, relación que la ha llevado al « drama sin solución en que me debato desde siempre : [...] Yo no pienso en español, sino en francés 》(1931: 15).

Es significativo este deseo de asentar fidelidad a una lengua que no es el castellano, en el inicio mismo de un emprendimiento cultural como

Sur

que tantos efectos indirectos tendría, a través de la traducción, sobre el castellano en la Argentina (Willson 2004). Al mismo tiempo, el ensayo constituye algo candorosamente, en el tiempo de la infancia, dos mundos separados : el del idioma castellano que remite a lo inarticulado, el del francés, que remite al pensamiento. Esta división -que Ocampo no esconde, que exhibe incluso, al decir de Sarlo,

espectacularmente, con esa sagacidad que tiene siempre Ocampo para desnudar sus relaciones con el mundo » (1996: 7) - tiene que ver con la estratificación social :el castellano, para Victoria niña, está en« los gritos de los peones », « exclamaciones que percibe como un género especial de mugidos.

No eran las palabras con que se piensa

. Y mi habla -mi español- la expresión verbal siempre me fue difícil- era, en otro plano, casi tan primitiva y salvaje » $(1931: 27)$;

$\ll$

ellas [las palabras francesas] me enseñaban que se puede escapar del silencio de otro modo que por el grito » (1931: 27). En este orden de cosas, empobrecer voluntariamente el castellano se vuelve signo de pertenencia de clase :

Muchos de nosotros empleábamos el español como esos viajeros que quieren aprender ciertas palabras de la lengua del país por donde viajan, porque esas palabras les son útiles para sacarlos de apuros en el hotel, en la estación y en los comercios, pero que no pasan de ahí. (1931: 28)

Imagino que el cincuenta por ciento de las cien palabras que componían nuestro vocabulario no figuraba siquiera en el

diccionario de la Academia Española. (1931 : 29)

Y cuando alguien pretende proferir como lengua ese español que equivale al grito o al mugido, da un indicio involuntario que delata su « cursilería » de« advenedizo », ajeno al« nos » excluyente : 
Cuanto más restringido era nuestro vocabulario, más a gusto nos sentíamos. Toda rebusca de expresión tenía una apariencia afectada. Emplear ciertas palabras, ciertos giros (que no eran, en realidad, otra cosa que gramaticalmente correctos), nos chocaba como puede chocarnos un vestido de baile en un campo de deportes o una mano que toma la taza con el meñique en el aire. (1931:28).

Además, debido a otro fenómeno, que sería curioso analizar, nos volvíamos al francés por repugnancia a la afectación. La penuria del español que aceptábamos nos lo tornaba imposible. Rechazábamos su riqueza ; rechazábamos esa riqueza como una cursilería. Nos disgustaba como una ostentación de lujo hecha de relumbrón y joyas falsas. El francés, por el contrario, era para nosotros la lengua en que podía expresarse todo sin parecer un advenedizo. (1931:28)

Es interesante, por otra parte, ver cómo el francés le permite a Ocampo no asumir el espacio que la rodea en términos cognoscitivos, sino instintivos, casi animales : el suelo argentino, que más tarde presentará a los varones franceses Drieu y Caillois como

, es la tierra que habla instintivamente al cuerpo y los sentidos, pero en la cual la cabeza se proyecta, gracias al francés, hacia otra parte :

Mientras yo estudiaba la gramática de Larive y Fleury, las ciencias de Paul Bert, la historia sagrada de Dury, cuántos deseos, cuántas miradas se evadían por la ventana hacia nuestros campos nuestros ríos nuestras calles. [...] Me acuerdo de ciertas noches tibias en que leía a Poe, traducido por Baudelaire, a la luz de una vela [...] « La caída de la casa Usher" ha quedado llena, para mí, de mugidos de vaca y de balidos de carneros. Un olor de alfalfa y trébol entraba por la ventana.

(1931:26-27)

Je suis heureuse d'avoir, si jeune, dans un jardin des bords de l'immense Rio de La Plata, près des jasmins et des eucalyptus, appris à goûter Racine, appris à aimer le plus français des poètes dans un paysage qui m'est cher, qui lui ressemble si peu et auquel il reste pourtant mêlé ; appris, enfin, à le considérer comme faisant partie

([1941] $1996: 190)$ d'un patrimoine inaliénable.

Tardes de infancia, imborrables, en que, después de haber chapaleado en el barro, del que mis uñas guardaban la huella, cargada de sol como un acumulador, corría a mis libros, ávida de volver a encontrar su atmósfera, en la que mi pensamiento se articulaba de pronto. ¡Palabras, queridas palabras francesas ! (1931:27)

Esto escribe Ocampo, tres años después de la publicación de «El idioma de los argentinos ", cinco después de « El tamaño de mi esperanza », en el tercer número de la revistaSur . Aunque Borges, a fines de los setenta, tras la muerte de Ocampo, habrá de definir el cosmopolitismo de Victoria como intimidad con los idiomas extranjeros (« conocer el slang

de los diversos idiomas, conocer lo que viene a ser como bromas de familia de los idiomas, esa es la verdadera intimidad con un país

-1979 : 331), es probable que los sucesivos y cada vez más sarcásticos distanciamientos con el idioma francés respondieran a una estrategia de posicionamiento respecto a Ocampo, « cactus en maceta

》

(Ocampo 1946 : 120), como le gustaba definirse, para quien el francés era « el único refugio de $[\mathrm{su}]$ pensamiento »(Ocampo $1931: 30)$ 
Teniendo en cuenta la prédica de los años veinte, es difícil en efecto pensar que tales ideas no irritaran a Borges ; el contexto de sociabilidad sin embargo impedía al miembro

Sur

contestar demasiado frontalmente. La respuesta parece haber venido gradualmente, en clave satírica, a lo largo de los años, por anécdotas contrapuestas, alusiones apenas encubiertas, burlas

45. En suAutobiografía ${ }^{46}$

, Borges por ejemplo satiriza el planteo de una problemática relación con el origen causado por el habla de una lengua extranjera, con la anécdota de Norah y las moscas, perfecto contre-pieddel episodio de los carneros narrado por Ocampo en «Palabras francesas »:

Me acuerdo de ciertas noches tibias en que leía a Poe, traducido por Baudelaire, a la luz de una vela [...] Era la época de la esquila. Durante el día se veía en un galpón a los peones hundir sus tijeras en la lana espesa. Uno de ellos iba y venía entre los demás, llevando en la mano una lata llena de una oscura mixtura que apestaba a alquitrán. Le llamaban a la vez de todas partes : "¡Médico, médico !", y él pintaba con este líquido misterioso las heridas que las tijeras descuidadas y presurosas infligían a los animales. Esto me impresionaba mucho. Sentía piedad por los carneros, miedo de las tijeras y, sin embargo, el espectáculo me fascinaba. Únicamente el pensar que

El escarabajo de orooEl diablo en el campanario me esperaban en casa podía romper el encanto. (Ocampo 1931 : 26-27)

En casa hablábamos español, pero el francés de mi hermana fue de pronto tan bueno que hasta soñaba en ese idioma. Recuerdo que una vez, al regresar a casa, mi madre encontró a Norah escondida detrás de una cortina de felpa roja, gritando asustada : "Une mouche, une mouche !" Parece que había adoptado la idea francesa de que las moscas son peligrosas. "Salí de ahí", le dijo : mi madre sin demasiado fervor patriótico. "¡Naciste y te criaste entre moscas !" (Borges [1970] 1999b : 43).

La reacción de « madre », hablada en criollo (« salíde ahí »

), devuelve brutalmente al principio de realidad y disuelve en el sentido más común el extático brote de lenguas, la farsa de origen ( "había adoptado la idea francesa »), la naturalización del idioma extranjero («

hasta soñaba en ese idioma »).

Las moscas, que son parte de una realidad negada por Norah, equivalen a los peones sin cara $-\ll$ tijeras descuidadas

- que no mira Victoria, en su sublimado afán compasivo por los carneros heridos. Poner un episodio a contraluz del otro permite, por lo demás, desarmar la ilusoria premisa de una tierra americana donde la referencia carece de signos y donde es necesario volverse al francés para designar. A su vez la anécdota, que ridiculiza indirectamente, en Norah y el francés, la relación simbiótica de Victoria, es narrada en inglés en las (sin duda anheladas por Ocampo) páginas de

\section{TheNew Yorker}

. Se trata en definitiva de oponerse a la adoración de una lengua y una cultura que para Borges deben ser usadas, no veneradas : la relación de paso, de viajero que conoce una o dos palabras para manejarse en la estación de trenes o el hotel que proponía Ocampo como analogía sobre el uso del castellano, debe ser revertida. En este sentido dirá Borges a Georges Charbonnier, en una entrevista radial de 1965 en « France Culture $»$ : 
Même si nous parlons le français d'une façon maladroite, ou un peu pénible pour vous, toute personne éduquée en Argentine peut jouir de la littérature française, même s'il y aura une difficulté pour parler avec un garçon de café ou à s'entendre avec un concierge, cette personne-là je crois n'aura pas de grandes difficultés pour

s'entendre avec Voltaire ou avec Hugo ou avec Verlaine, ce qui est bien plus important, évidemment, non, que savoir commander un dîner ou parler de malles ou d'avions avec n'importe qui.

Otro flanco de ataque indirecto es la figura, señera para Ocampo, de Paul Valéry. El inicial y sincero entusiasmo de Borges por el creador de Monsieur Teste, « la invención más

([1937] 1996 : 58), se transforma paulatinamente en burlona síntesis del literato francés, hasta culminar, como lo advierte la crítica

y lo ficcionalizó bellamente Michel Lafon (2009), en los ambiguos lazos que unen las figuras de Pierre Menard con Paul Valéry. Ahora bien, basta con leer el retrato que Victoria Ocampo hace del rostro de Valéry en su temprano análisis del

Cimetière marin

(Ocampo 1933), o el relato de su primer encuentro en París, o la semblanza que le dedica tras su muerte (Ocampo 1946), para medir la intensidad de su fervor. Un fervor que no difiere demasiado del que profesan la baronesa de Bacourt, Madame Henri Bachelier y la condesa de Bagnoregio, circunvalado personaje plural de admiradoras de Menard, cuyas distintas facetas evocan la figura de Ocampo ( socialites

, femmes de lettres, polemistas, exégetas, seguidoras que poseen «ávido[s] álbum[es] » , etc.). No parece del todo un azar, desde esta óptica, el adjetivo « victorioso » en la « definición de la condesa de Bagnoregio »que produce Menard:

q) Una "definición" de la condesa de Bagnoregio, en el "victorioso volumen" -la locución es de otro colaborador, Gabriele d'Annunzio- que anualmente publica esta dama para rectificar los inevitables falseos del periodismo y presentar "al mundo y

a Italia" una auténtica efigie de su persona, tan expuesta (en razón misma de su belleza y de su actuación) a interpretaciones erróneas o apresuradas. (1939 : 445-6)

Allende la referencia, casi obvia, en el « victorioso volumen [...] que anualmente publica

", a la publicación, a partir de 1935 en laRevista de Occidente, de los sucesivosTestimonios que da a conocer Ocampo, puede encontrarse, en el tono mismo del narrador de « Pierre Menard...

$\gg$

, la admiración que Ocampo ostenta por Valéry en la conferencia que dicta, en 1933, en la Sociedad de Amigos del Arte sobre « El cementerio marino

. Los análisis de Ocampo podrían fácilmente superponerse con la voz del narrador pedante y adorador de la primera parte del cuento :

[...] el encanto gris de lase

mudas, que son toda la dulzura, todo lo indeterminado en que se hunden las rimas femeninas en el verso francés, se resuelve en este poema de Valéry en precisión

fulgurante. Precisión fulgurante de las dos rimas masculinas, la primera de las cuales cae neta, fuerte, entre las cuatro rimas femeninas, mientras la segunda se aprieta como un nudo corredizo al final de la estrofa. (1933: 259) 
L'insecte net gratte la sécheresse.

[...] No sé exactamente por qué ese verso, de imagen auditiva perfecta, es para mí, en el Cimetière marin

la frasecita de la sonata de Vinteuil que me evoca el espíritu mismo del poeta. La aliteración que contribuye a su encanto está confiada a consonantes, a las más descarnadas consonantes del alfabeto. Las

tesy laseses

: la admirable dureza de este verso quema, sin embargo, quema como un fuego sin materia. Me evoca a Valéry en cuerpo y alma. Se asemeja a su rostro enjuto, ese rostro soberanamente preciso, hecho de bellas aristas, rostro cerrado, pero en el que se abren unos ojos llenos de luz líquida. Este rostro secreto de aficionado a abstracciones se traiciona en esos ojos claros y vulnerables de poeta. (1933 : 267)

Un año antes, en 1932, había aparecido el prólogo de Borges a la traducción de Néstor

, donde celebraba en la versión de su amigo el haber « cumplido con los rigores métricos del original » (152); el juego con esos rigores se vuelve, seis años más tarde, en el cuento publicado en

Sur

, parte de los ejercicios formales que componen la obra visible de Menard : "una transposición en alejandrinos del

Cimetière marinde Paul Valéry (N.R.F., enero de 1928) »

. Ahora bien, esa «transposición en alejandrinos»

es también parte de la « invectiva contra Paul Valéry »

, en la medida en que ataca un punto central, heredado de Mallarmé, de su poética : la inexorable necesidad de la estructura métrica elegida, sobre la cual por otra parte insistía Ocampo en su análisis ( « la frasecita de la sonata de Vinteuil $\gg)$.

Cada una de estas pequeñas pullas perpetradas en contra de Valéry de alguna manera toca a Victoria, y con ella, su visión del francés

48

. Burlarse de Valéry es menos, en esta óptica, un ataque personal en contra del autor de los

Cahiers

, que un gesto de rechazo hacia el idilio de Ocampo con los « ojos claros y vulnerables del

poeta

(1933 : 267). De alguna manera el propio Borges lo revela en el cuento : « Esa invectiva, dicho sea entre paréntesis, es el reverso exacto de su verdadera opinión sobre Valéry. Éste así lo entendió y la amistad antigua de los dos no corrió peligro »(1939 : 446).

Una relación antigua y un conocimiento de la lengua de Valéry que por cierto venían de lejos, como fácilmente puede comprobarse en cualquier biografía de Borges. 


\section{De los « Frères de l'Ultra 49 » a la « boussole des précieux ${ }^{50}$ »}

... les gallicismes, aussi fréquents dans ma prose espagnole

que le sont les hispanismes dans mon français. Borges, carta del 1 de diciembre 1919

La carta de los compañeros del Collège Calvin pidiendo que lo aprueben en la materia

, el desconocimiento del propio apellido pronunciado « a la manera francesa, con una sola

sílaba

por los profesores ginebrinos, los codazos de los amigos cuando debía contestar en francés (1999b : 42) : Borges arma el relato de su inicial falta de empatía con la lengua francesa en base a dos o tres anécdotas originadas en la estadía en Suiza, que repite, siguiendo un método que le es familiar, en entrevistas y diálogos, y sintetiza en la

autobiografía

51

. En la mitología armada por el Borges de 1970 en torno a sus años de formación, el francés parece interesarle menos que otras lenguas, por ejemplo el latín del Collège que lo vincula con el abuelo Haslam (Borges 1999b : 28) ; o el alemán del autodidacta que traduce, a principios de los años veinte, poetas expresionistas para las revistas Grecia,CervantesyUltra ${ }^{52}$

; o el inglés, voluntariosa, virtuosamente innato. Pasar de una lengua a otra, ser políglota : la lectura retrospectiva hecha en los años setenta presenta el francés como una lengua más -no la primera, a pesar de la estadía en Ginebra y del colegio secundario en francés- dentro del abanico de idiomas que el Borges arrivémaneja y critica con displicencia, como se vio en el texto deThe New Yorker

(1970 : 46). La condición de políglota y la fría valoración del francés se vuelven de esta manera la marca del ilustrado, el signo de un saber que trasciende el chato origen argentino sin reducirse al (tan argentino) manejo del francés : la autobiografía enumera en consecuencia, con hábil modestia, el inglés, el alemán, el latín, el italiano, el francés como lenguas de formación adquiridas durante la Gran Guerra

53. Esto, en 1970.

Una relectura del epistolario que el joven Borges mantiene, cincuenta años antes y en francés, con su compañero Maurice Abramowicz viene sin embargo a matizar apreciablemente este proceso de equiparación entre lenguas. En estas cartas, escritas 
, el francés de Borges, con su jerga estudiantina, sus faltas de ortografía, sus hispanismos y su gramática clásica y fantasiosa, es mucho más que una lengua de formación y cultura :

el francés es la lengua de pertenencia a un grupo (los estudiantes del Collège Calvin, Ginebra), así como la lengua de legitimación literaria que habilita el proselitismo, la escaramuza polémica y la intriga de cenáculo. Paralelamente, como en sordina, se dibuja en estas cartas un referente que inquieta al joven Borges, ese referente es « BuenosAires » : « Le retour à Buenos-Aires m'ennuie -mais comment !

Je prends par ci par là de [sic] renseignements sur cette étrange contrée » $(21,134)$; «Mon départ pour Buenos-Aires (cinq ou six mois d'échéance encore !) me trouble vaguement » $(13,102)$.

Buenos-Aires

, no Buenos Aires : el guión galicado contrasta con los errores de sintaxis y gramática, las faltas de ortografía, las menciones del acento al hablar, en definitiva : las marcas de la extranjería. En esa tensión -antes quizá que en la calculada posesión simbólica de una lengua de cultura- se juega a nuestro entender el interés de esta primera correspondencia entre Borges y Abramowicz.

\section{Abramowicz ${ }^{55}$}

integra el grupo de amigos que Borges celebra por medio de la escritura, en un gesto que en él vale como marca real de aprecio. «Salve, amigos lejanos, Whitman, Isaac, Adriano, Abramowicz, Johannes Becher... »escribe en "Paréntesis pasional ${ }^{56}$ », un texto publicado enGrecia en 1920 ; el poema « Señal ${ }^{57}$ »está dedicado a Maurice Claude, pseudónimo de Abramowicz ${ }^{58}$; una nota al pie vuelve a mencionarlo en « Tres versiones de Judas ${ }^{59}$ " en 1944 ; dos textos de homenaje aparecen finalmente enLos Conjurados : « Elegía » (1985 : 33) y « Abramowicz »

(1985 : 35). De estas menciones, quizá la más interesante sea la del cuento, en tanto remite doblemente a la correspondencia : primero, porque la nota al pie contiene una cita en francés ; segundo, porque la problemática en torno a Judas discutida con Abramowicz ya está presente en una carta escrita veinticuatro años antes, también en francés $(4,72)$ :

Maurice Abramowicz observa : «Jésus, d'après ce scandinave, a toujours le beau rôle ; ses déboires, grâce à la science des typographes, jouissent d'une réputation polyglotte ; sa résidence de trente-trois ans parmi les humains ne fut en somme, qu'une villégiature ». ([1944] $1996: 516-517)$

[Silverio Lanza] écrit une vie imaginaire de Judas Iscariote et il nous raconte que sa mère fut une prostituée de Garizín... Judas quitte son pays pour aller à Jérusalem et, déjà homme, revient à Garizín. Alors... « près de la ville et dans les proximités du chemin, il trouva une fille et il arrangea avec elle le prix du plaisir. Quand il l'eut [sic] atteint ils parlèrent ensemble et comme il lui dit qui il était, elle s'écria : « Mon fils ! » Et Judas répondit : « Eh bien si tu es ma mère, rends-moi mon argent ».

$(4,72-74)$

En la dinámica de las cartas, la anécdota narrada (la relación de Judas con una prostituta que resultó ser su madre) es perturbadora y ligera a la vez, porque retoma una temática recurrente del diálogo epistolar : las mujeres. Las mujeres que se miran, que se cruzan en la calle, que se tratan socialmente ; las fantasías en torno a la sensualidad observada, el relato de proeza, el sexo :

Une jeune fille [...] s'est ajoutée à présent à notre groupe. Elle est assez jolie, elle a 23 ans et elle a une pose de gamine. Elle rit elle crie elle fait un sale tapage. Toute la journée les deux amies sont à se taquiner à s'embrasser à se donner des coups de pied, à s'égratigner : genre Pierre Louys [sic]. $(11,92)$ 
Puis [...] la petite me parla de son désir d'aller à Buenos-Aires et du chagrin que cela lui faisait de me voir sans croyances religieuses. Elle me proposa d'abjurer mes

blasphèmes à l'égard de la Vierge, d'aller à la messe avec elle, de me confeser [sic] et de communier ensemble. Charmant ! $(11,92)$

La plume qui se fatigue. [...] L'alcool qui se dissipe. La nuit et les femmes ! et les balcons cachés ! et la jeune fille (13 ans !) qui ce matin me fit le haut cadeau de son sourire ! et toi, mon cœur qui dans la nuit bondit ! $(20,130)$.

Puis à la roulette j'avais joui d'une veine inouïe -pour moi- (60 pesetas avec un capital d'

une

peseta !) et qui me permit de triompher 3 nuits de suite au bordel. Une blonde somptueusement cochonne et une brune que nous appelions La Princesa et sur l'humanité de laquelle je m'enivrais comme sur un avion ou sur un cheval. (Une Catalane, pardonne-moi) ! Maintenant la gloire s'est éteinte. Je me sens « tel qu'un orphelin pauvre sans sœur aînée ». Vraiment j'ai aimé cette Luz qui me traitait en gamin et dont les gestes étaient d'une indécence ingénue.

Elle ressemblait à une cathédrale et à une chienne. $(24,146)$

59

El tono general de las citas y la notable metáfora final de la última parecía una catedral y una perra

- se enmarcan en una larga tradición de vanagloria masculina que Borges estiliza (un Chansons de Bilitis poco) mencionando a Pierre Louÿs, autor de las sáficas

(1894). Así, pues, los códigos evocados con el amigo generan complicidad a partir de los tópicos propios de la bohemia estudiantina : mujeres, juergas, alcohol (« Mon étape à Madrid : alcohol, camaraderie, doutes et très modestes festins

$-6,78$ ), pero también vestigios de las grillas escolares («L'après-midi, j’ai des leçons, des leçons de latin et d'algèbre, pour me préparer au Baccalauréat Français l'année prochaine »

. -1, 58) y signos de reconocimiento estudiantil. El francés de pasillo de colegio aparece de hecho en las salutaciones (« Je t'embrasse comme un ours

»-8, 86 ; « Je te prie de me répondre à la $n$ vitesse au cube »

$-14,108$ ), en el coloquialismo (« merde pour les catalans!»

$-6,78$. « La descendence de Whitman m'enmerde [sic]. Yankee funeste ! » -20, 130. «J'ai reçu deux lettres d'Isaac dans un ton mixte d'altitude directoriale et de ça biche mon vieux copain »

$-9,89$, yo subrayo), así como en los latinazgos, guiños a la formación común en el Collège

Calvin :

Pour cette fois-ci, vale, mon cher ! $(3,68)$

Tu me pardonneras de te parler métier mais je suis saturé de discussions

esthétiques et il faut bien que ces lignes s'en ressentent quelque peu. Satis ! $(4,74)$

Je te serre très cordialement la main,carissime frater $(4,74)$

FESTINA CELERITER ! ! $(16,118)$.

Esta práctica de un francés coloquial y colegial, cargado de marcas de pertenencia, es reforzada dialectalmente por un léxico que define identidad : el francés de las cartas a Abramowicz es sobre todo el francés de la ciudad de Ginebra, desde el uso del ordinal

»(en vez del hexagonal « quatre-vingt dix »), hasta las comparaciones con el Journal de Genèveme

, pasando por la burla a los estereotipos sobre Suiza que circulan en España ${ }^{60}$ 
$(1,60)$, las críticas a Francia $(3,68)$ o la evocación apócrifa y mordaz del poeta de la bohemia española Pedro Luis de Gálvez en la valesana y seria ciudad de Martigny $(5,76)$.

« T’avouerai-je que cela m'a fait une impression crépusculaire et (parlons genevois !)

moche?»

$(6,81)$ : el giro traduce una fuerte voluntad de pertenencia (o de comunión con Abramowicz) ya que, en rigor de verdad, « moche "no es una forma particularmente ginebrina, sino una voz familiar para decir «feo » en cualquier variante del francés.

De manera general, todo el epistolario revela un disfrute muy hondo en el manejo de lenguas : párrafos enteros en alemán $(11,92)$, frases o sintagmas en español diseminadas en los márgenes (y unidas generalmente al sarcasmo 61

), locuciones latinas : Borges pasa de una lengua a otra en gesto gozoso, de poder. De una lengua a otra, aunque siguiendo una jerarquía tácita en la que el francés es base : si el catalán es « un patois hideux

$(15,110)$, hay un orgullo implícito en las experiencias de escritura y de habla que mezclan el español con el francés y el francés con el español :

Que fais-tu mon ami? Moi tout ce dernier temps j'ai travaillé régulièrement comme une machine, sans grand enthousiasme il est vrai mais barbouillant mes trois ou quatre pages par jour... [...] C'est le premier jet qui est le plus difficile. Après ça va tout seul de corriger, de supprimer les mots qui riment, les mots qui se répètent et les gallicismes, aussi fréquents dans ma prose espagnole que le sont les hispanismes

$(2,65)$

dans mon français.

La satisfacción por la posesión del francés deriva en dos efectos, opuestos entre sí : el desprecio hacia quien lo ignora, el complejo por las propias deficiencias en el manejo de

Desprecio por Isaac del Vando Villar, director deGrecia

la lengua.

: «Dans la composition de ta lettre éventuelle au grand Isaac je te conseillerai [sic] de rechercher les qualités classiques de la clarté, la sobriété u.s.w. [und so weiter] (Les connaissances françaises de l'ample et arborescent chef de sont plutôt corticales)»

Grecia $\quad(8,86)$.Es en el « und so weiter »

abreviado y en la mención irónica y sintética de los rasgos tradicionalmente atribuidos al francés como lengua (

clarté, sobriétéque él, Borges, maneja) donde se adivina el goce por el propio saber.

Y más adelante : «Isaac t'a-t-il écrit en français ?Garfias a du [sic] être son secrétaire »

$(10,90)$. Hay sin embargo un contrapeso al orgullo : la conciencia del acento como síntoma involuntario de una limitación y de un origen que no pueden disimularse : « Sureda crie

Les fleurs du malavec un accent auquel, le mien est dans la tradition française la plus pure $»$

$(12,96)$, apunta, usando un giro sintáctico algo extraño. Un tiempo antes había transcripto el diálogo con un joven español que lo examinaba inquisitivamente : « Mais vous, vous êtes pas Suisse, vous êtes...

Américain, Argentin ?...Moi 
: Argentin, de la très noble cité de Buenos Aires. Le Jeune Homme (d'un ton rusé et perspicace) : Je l'avais deviné à votre accent ». $(1,62)$. De esta manera, constantemente, vuelve la temática en torno al idioma, al valor que su posesión confiere y que Borges exhibe ante el compañero suizo, aunque no sólo ante él.

En un estudio sobre la correspondencia de Flaubert, Claudine Gothot-Mersch (1991 : 15) releva como marcas principales del género la falta de clausura y la disociación entre el destinatario original y el público posterior : « [...] alors que, dans une œuvre littéraire, tout est pesé en fonction du lecteur, avec la lettre celui-ci se trouve devant un texte qui n'a pas été écrit pour lui, dont les allusions, les obscurités n'ont pas été calculées en fonction de lui, ni le contenu, ni la façon dont il est présenté ».

No es ésta sin embargo la dinámica en la correspondencia Borges-Abramowicz : sorprende en la lectura continua el lento dibujarse de un tema que aparece una y otra vez, como buscando desplegarse por completo, y que Borges denomina, ya en 1919, su « trajectoire littéraire

. Y en efecto nunca la anécdota, más allá de su destinatario, pierde de vista el objetivo : legitimar, dar un nivel a la tarea de escritura. Una continuidad retórica y narrativa permite seguir la exposición de un proyecto literario construido a partir de núcleos sociales (las confidencias al amigo que permiten la escritura), culturales (la aventura del ultraísmo) y lingüísticos (el manejo de lenguas). En este sentido, el francés cumple una función específica en el proceso de legitimación en tanto confiere desde lo simbólico -

como

la

lengua de cultura del siglo XIX- un estatuto de legalidad del que Borges es consciente, a pesar de la manía de sus contemporáneos americanos « de vouloir que l'Amérique ne copie rien de l'Europe

(viene hablando de Huidobro -18, 122). Leída desde esta perspectiva, «Chronique des Lettres espagnoles $62 》$

([1919] 1997 : 22-24), la primera (agosto de 1919) de las muchas reseñas críticas que Borges redactará luego en español, toma otro cariz. El texto, escrito en francés, corregido por Abramowicz y publicado por su mediación en el « Journal littéraire »La Feuille

, de Ginebra, viene de alguna manera, discreta y simbólicamente, a marcar la entrada en el campo literario.

Tanto las cartas dirigidas a Abramowicz como las destinadas a Sureda revelan en Borges, aunque de manera distinta, una clara y temprana conciencia de las categorías de evaluación que rigen el sistema literario : la presencia en diarios, el reconocimiento de otros poetas, el valor simbólico de lo que se es y lo que se parece : « En ce qui concerne ma trajectoire littéraire, je constate avec plaisir que cette mienne et personelle [sic] gloriole que l'ultraïsme m'a donné, rayonne sensiblement : Rogelio Buendía, un poète andaluz

que je ne connais pas personellement [sic], me demande de collaborer dans sa nouvelle revue Centauro » 
$(15,110)$. En el mismo sentido hay que entender el comentario sobre Valle Inclán, la evaluación de su peso en bolsa : "Pour un monsieur qui vise au génie, Don Ramón del

Valle-Inclán a accouché d'une bêtise avec son "Estética de la mujer de color".

Mais la signature vaut... »(sobre el número deGrecia

del 1ero de agosto 1920 -yo subrayo, 11, 95). También, la alegría por las respuestas y el reconocimiento de Klemm y Heynicke, poetas expresionistas que Borges traduce para Grecia :

T’ai-je raconté que Klemm et Heynicke ont répondu à mon envoi du numéro de

Grecia

contenant mes versions de leurs poèmes, le premier avec une lettre style Whitman

et un livre de poèmes avec dédicace, et l'autre par une lettre pleine aussi de l'huile

de l'amitié et un portrait et la promesse de m'envoyer un sien drame expressioniste

[sic] ? « Mon âme, garde-toi de [sic] petites victoires ! », dit Zarathoustra » $(17,120)$.

La relación de amistad sigue implicando un código de juego con los idiomas : Borges traduce un poema de Abramowicz al español : « Un chant résigné

»/ « Un canto resignado ${ }^{63}$ »; Abramowicz corrige la « Chronique »

de Borges en francés ; Borges envía al amigo ginebrino un mallarmeano poema de Sureda traducido al español (« L'encensoir du néant/ consommait un vaste holocauste [...]

») : « Tu me parles de Sureda. J'ai un poème de lui dans ma poche qu'il me donna le jour de nos adieux. Le voici versé au français. Qu'en dis-tu ? [...] Je trouve le cinquième et le sixième vers très forts

${ }^{64} »(13,104)$.

La práctica de la traducción es una faceta más de su rol de mediador, esto es, de agente que promueve la difusión del ultraísmo (él mismo se define como « hilo conductor

»). Las cartas muestran que Borges conoce perfectamente las etapas, las intervenciones, los ritos en torno al hecho literario. Más tarde se burlará de ellos y los asignará exclusivamente al campo literario francés :

[...] En Francia cada escritor quiere saber exactamente lo que hace y, mediante manifiestos y análisis, anticipa el lugar que le corresponde en la evolución de las letras. El extravagante no ignora su extravagancia y sabe que ésta no será otra cosa que un rasgo en el dibujo secular. Asistimos así al curioso espectáculo de páginas metódicamente incoherentes o pueriles a las que respalda una rigurosa justificación en prosa cartesiana. De este modo se ha creado un mundo de cenáculos y sectas, que libran batallas incruentas, no sólo movidas por un afán de propaganda comercial o de alarde romántico, sino por la voluntad de llevar hasta sus últimas consecuencias cada teoría estética 66.

Pero las cartas juveniles revelan un ejercicio similar en la propaganda : batallas campales en la más pura tradición de la de

Hernani, maniobras para generar peleas literarias ${ }^{67}$, « réplica ${ }^{68}$ », « contestación » , prácticas varias de l'« orgie polémique » $(13,102)$ :

Dans le Festival Ultraïste à Madrid, un grand scandale. Les cris et les hurlements d'indignation du public ont totalement noyé l'audition de 2 miens poèmes. Les œuvres des autres frères de l'ultra ont subi le même sort. $(22,140)$

Demain je monte à Valldemosa, voir Sureda et concerter avec lui les moyens pour avoir une polémique avec l'anonyme, ce qui serait excellent comme propagande et très amusant, en outre [sic]. $(15,110-111)$ 
[...] nous avons fabriqué, Jacobo et moi, deux répliques, l'une ironique, logique, mesurée, signée Sureda et qui a paru avant-hier à Palma ; l'autre violente, âcre, proclamatoire, signée J.L.B. que j’ai expédiée hier et qui -hélas- ne se publiera peutêtre point, vu que notre ennemi est persona gratachez tous les rédacteurs des Journaux. $(16,114)$

J'ai a [sic] ultimer un travail d'une large importance : l'écriture du Manifeste synthétique du groupe ultraïste de Mallorca qui paraitra le 15 février dans la revue

locale

Baleares.Cela m'amuse cette combine ! $(22,140)$.

Estas mismas intrigas aparecen en el epistolario con Sureda ${ }^{69}$

, aunque con mayor urgencia y menor confianza. Sureda es agente activo de las polémicas, pero Abramowicz, alias Maurice Claude, es « frère dans la race et l'ultraïsme »(17, 120). « Hermano en la raza »

, escribe Borges, aludiendo a una deseada ascendencia judía que lo hermanaría aún más con Abramowicz, « lírico ironizante judío

»(a Sureda, 3, 164) :

D'abord -et ceci flatte cette lubie judaïque que tu as souligné chez moi maintes foisje viens de découvrir dans un bouquin d'un monsieur Ramos-Mejía, historien grave, très connu à Buenos-Aires et tout à fait idiot et véridique, que les Acevedo (la

famille de ma mère) sont de [sic] séphardites, de [sic] juifs portugais reconvertis. Je ne sais trop comment célébrer ce ruisseau de sang israélite qui coule dans mes

veines.

$(15,110)$

La correspondencia en francés piensa en su lector futuro. Prueba de ello, también, es su dimensión programática, la forma en que construye, en paralelo a las confidencias, los borradores de la tradicional carta de escritor que expone una poética, con sus marcas temáticas y retóricas. Si el relato de intriga contado a Abramowicz se duplica en las cartas a Sureda (y vice-versa), no así la exposición de principios, que parece reservada al epistolario en francés, en un tácito e involuntario reconocimiento del arte con que el idioma de Boileau, Rimbaud o Breton teje «

manifiestos y análisis »,«

páginas metódicamente incoherentes o pueriles a las que respalda una rigurosa

Borges 1999c : 63-64).

justificación en prosa » (

El proselitismo ultraísta, en particular la carta 7 a Abramowicz (mayo de 1920), retoma en efecto las marcas tipo de los manifiestos y de las cartas-poética : definiciones asertivas ( « nous voulons ( 3 ou 4 de nous) détruire la rhétorique, la conception architectonique du poème, les festons et les astragales comme disait Boileau » $-7,82)$; plural de grupo (« Nous voulons condenser, ne dire que l'essentiel »); definición de lo que no debe hacerse : « les fabricants de sonnets qui vont jusqu'à bâtir 13 lignes indifférentes pour préparer l'entrée en scène de la dernière, la raison d'être de leur sonnet, ce qui est absurde »; « une autre chose à lutter contre [sic], c'est la continuation de l'image par

l'auteur $[. .$.

$(7,82)$. Varias de estas ideas aparecen en textos en español escritos para la misma época : « [...] Nosotros los ultraístas [...] desechamos todo lo arquitectónico, es decir todo lo ficticio que se disfraza de belleza, y buscamos inéditas trayectorias 
; « los literatos nos brindan el deplorable espectáculo de una cuadrilla de gimnastas ejecutando, con mayor o menor virtuosidad, la serie de trucos consagrados por el tiempo como más patos para impresionar a su público. Estos trucos (antítesis, frases de relumbrón, quincallería verbal) [...] » (octubre 1920, 1997 : 90). En algún punto el francés, y Abramowicz como interlocutor, parecen funcionar como pretexto o borrador para el desarrollo de los argumentos. La carta 7 concluye significativamente con el deseo de la conversación del amigo y el cansancio de la retórica : « Mais assez ergoté. Verbalement je me ferai comprendre bien mieux. Puis : des exemples, des objections que je devine sans arriver à les préciser, de [sic] définitions de termes » $(7,84)$.

En francés las confidencias, en francés los borradores de la poética. Este doble uso del idioma explica quizá la insólita (y única) carta escrita en francés a Jacobo Sureda, mallorquín, en marzo de 1922 y desde Buenos Aires $(32,209)$. En ella narra Borges enardecido su amor por Concepción Guerrero, así como el alejamiento de los círculos ultraístas :

Je vais de temps en temps au cénacle ultraïste par moi inicié, et qui ne semble pas

souffrir énormément de mes absences. (On me trouve hérétique, canaille, vieuxjeu : de sérieux jeunes gens qui se nourrisent [sic] de mes opinions et paradoxes d'il y a trois mois, me les jettent maintenant à la figure. Ils jurent par la métaphore, ils comprennent à présent tout à fait bien la Proclame que j'avais fait [sic] pour

Prisma, et il est naturel qu'ils me trouvent inutile.Sic transit minima gloria mundi.)

[...] J'écris de [sic] choses prudentes, j'étudie les classiques, je viens d'acheter le Romancero del Cid[...]

¿Por qué, para qué componer esta carta en francés? Una primera respuesta, de sentido común, es que Borges está contestando en francés una carta recibida en francés. Otra hipótesis posible es que esta carta, que comunica a Sureda el cierre de la etapa ultraísta y se adentra en la confesión sentimental, vuelve instintivamente hacia el idioma que acompañó la juvenilia y la aventura del ultraísmo y que ahora, en Buenos Aires, 1922, empieza a perder peso ante problemas lingüísticos nuevos.

¿Subsisten rasgos formales del modo de escritura del francés insertos en su prosa ? En

e este comercio tan cercano con el francés, su estructura y sus usos, le quedarán a Borges habilidades que a fines de los treinta, tras la discusión sobre la lengua de los años veinte, reaparecerán en su escritura. Hay, en primer lugar, una productividad inmediata en las citas que elige hacer en francés, en la irónica eficacia de ciertas expresiones particularmente sintéticas : « Las jergas. Ce pluriel est bien singulier »(1941: 32), « El investigador de Vacarezza intenta elmot juste »

(1941 : 33), « [...] dos o tres adjetivos en letra gótica bastaron para que Julius Rothe admitiera la preeminencia de Hladík y dispusiera que lo condenaran a muerte, pour encourager les autres »(1943: 509). Borges recupera el uso delavis satirica

del idioma de Molière, en consonancia y reconciliación con una tradición argentina que va de la

causerieincisiva al uso escrito instalado en la cultura letrada ${ }^{70}$ , y que a su vez incluye las prácticas sociales de las clases altas : una síntesis de esta triple adscripción puede observarse en las infinitas expresiones burlonas en francés mechadas

en el

Borges

de Bioy Casares. Esto confluye, al decir de Ana María Barrenechea (1953 : 220), en los« amaneramientos de literato y socio del Jockey Club »y los« desplantes de niña de sociedad 
que figuran en las obras en colaboración ; también en Carlos Argentino Daneri y el narrador de

«Pierre Menard», cuya prosa inicial transpira intencionales galicismos : Decididamente , una breve rectificación es inevitable »

(1939: 445, yo subrayo). Los talentos de Menard, por su parte, que incluyen" un examen de las leyes métricas esenciales de la prosa francesa, ilustrado con ejemplos de

SaintSimon

»0« un obstinado análisis de las "costumbres sintácticas" de Toulet »

(1939: 446) son a su vez los de Borges, que posee herramientas suficientes para desarmar y atravesar una lengua y su tradición : es, en suma, el refinamiento, el júbilo, el manejo del escenario que se adivinan en el hallazgo que supone traducir en « Pierre Menard... »(1939 : 446)laAguja de navegar cultosde Quevedo como

La Boussole des précieux.

Los últimos estudios críticos han rastreado de hecho, como en el caso del inglés, la productividad mediada por sus traducciones del francés en el proceso de creación

71

. Productividad que Borges, a su vez, sabrá hacer valer en la construcción de su figura pública, por ejemplo en las entrevistas de radio con Georges Charbonnier en France Culture, con el moroso fraseo de extranjero culto que a la manera porteña añade, al final de las frases, el escéptico « ¿no?

»

argentino traducido al francés, invirtiendo ya definitivamente los valores simbólicos que constituían, al inicio del siglo, la « heterogénea lengua vernácula de charla porteña ».

\section{BIBLIOGRAFÍA}

Abeille, Luciano.« Influencia del francés sobre la sintaxis argentina », en Idioma nacional de los argentinos.Buenos Aires : Colihue/Biblioteca Nacional, 2005, pp. 325-334.

Alfón, Fernando. Estudio liminar », enLa querella de la lengua. Antología. Buenos Aires : Biblioteca Nacional, 2013, pp. 11-68.

Arnoux, Elvira y Bein, Roberto. « Posiciones de Jorge Luis Borges acerca del idioma nacional », en Borges. Buenos Aires : Biblioteca del Congreso de la Nación, 1997, pp. 19-30.

Attala, Daniel.Macedonio Fernández.«Précurseur »de Borges.Rennes : PUR, 2014.

Balderston, Daniel.« Menard and his Contemporaries: The Arms and Letters Debate », en Out of Context: Historical Reference and the Representation of Reality in Borges.

Durham \& London: Duke UP, 1993, pp. 18-33.

Barrenechea, Ana María.« Borges y el lenguaje ».Nueva Revista de Filología Hispánica, vol. VII (1953) : 551-569.

Bioy Casares, Adolfo.Borges. Buenos Aires : Destino, 2006. 
Borges, Jorge Luis. [1919]. « Chronique des lettres espagnoles. Trois nouveaux livres »,La feuille , Ginebra, recogido enTextos recobrados.1919-1929. Buenos Aires : Emecé, 1997, pp. 22-24.

Borges, Jorge Luis. [1923]. « A quien leyere », enFervor de Buenos Aires, Buenos Aires, Impr. Serantes, recogido enTextos recobrados. 1919-1929 . Buenos Aires : Emecé, 1997, pp. 162-164.

Borges, Jorge Luis. [1925]. « Ejecución de tres palabras », enInquisiciones . Madrid : Alianza, 2008, pp. 167-174.

Borges, Jorge Luis. [1925a]. « El idioma infinito »,Proa, segunda época, julio 1925, recogido en El tamaño de mi esperanza(1926). Buenos Aires : Debolsillo, 2012, pp. 35-38.

Borges, Jorge Luis. [1925b]. « Al tal vez lector», enLuna de enfrente . Buenos Aires : Editorial Proa, recogido enTextos recobrados. 1919-1929. Buenos Aires : Emecé, 1997, p. 219.

Borges, Jorge Luis. [1926a]. « Palabrería para versos ». Buenos Aires:La Prensa , 2nda sección, 2 de mayo de 1926, recogido enEl tamaño de mi esperanza (1926). Buenos Aires : Debolsillo, 2012, pp. 39-43.

Borges, Jorge Luis. [1926b]. « La adjetivación ». Buenos Aires:La Prensa , 2nda sección, 16 de mayo 1926, recogido enEl tamaño de mi esperanza (1926). Buenos Aires : Debolsillo, 2012.

Borges, Jorge Luis. [1926c]. « Invectiva contra el arrabalero ». Buenos Aires:La Prensa , 2nda sección, 6 de junio 1926, recogido enEl tamaño de mi esperanza (1926). Buenos Aires : Debolsillo, 2012.

Borges, Jorge Luis, [1926d]. « Profesión de fe literaria ». Buenos Aires:La Prensa , 2nda sección, 27 de junio 1926, recogido enEl tamaño de mi esperanza (1926). Buenos Aires : Debolsillo, 2012.

Borges, Jorge Luis. [1927]. « Sobreel meridiano de una Gaceta »,Martín Fierro, 42, p. 7, recogido en Textos recobrados. 1919-1929. Buenos Aires : Emecé, 1997, pp. 303-304.

Borges, Jorge Luis. [1928]. « El idioma de los argentinos »,La Gaceta Literaria, Madrid, recogidoen El idioma de los argentinos(1928). Buenos Aires : Debolsillo, 2012, pp. 223-236.

Borges, Jorge Luis. [1932]. Prólogo aEl cementerio marino

de Paul Valéry, trad. de Néstor Ibarra, Buenos Aires, Les éd. Schillinger, recogido en Obras Completas IV. Buenos Aires : Emecé, 1996, pp. 151-154.

Borges, Jorge Luis. [1941]. « Fragmento sobre Joyce »,Sur, año X, 77, recogido enBorges enSur (1931-1980). Buenos Aires : Emecé, 1999, pp. 167-169.

Borges, Jorge Luis. [1939]. « Pierre Menard, autor delQuijote”,Sur,año IX, 59, recogido en Ficciones, Obras Completas I.Buenos Aires : Emecé, 1996, pp. 444-450.

Borges, Jorge Luis. [1952]. « Las alarmas del doctor Américo Castro »,Otras inquisiciones, en Obras Completas II.

Buenos Aires : Emecé, 1996, pp. 31-35. [Inicialmente publicado como reseña : « Américo Castro : La peculiaridad lingüística rioplatense y su sentido histórico

»,Sur(1941) $86: 66-70$.

Borges, Jorge Luis. [1963]. Prólogo aEvaristo Carriego, Versos de Carriego . Buenos Aires : Eudeba, recogido enPrólogos con un prólogo de prólogos,enObras Completas IV. Buenos Aires : Emecé, 1996, pp. 42-44. 
Borges, Jorge Luis. « Autobiographical Notes »,The New Yorker, 19 de septiembre de 1970 : 40-99.

Borges, Jorge Luis.Obras Completas.Buenos Aires : Emecé, 1974.

Borges, Jorge Luis.« Prólogo de prólogos »,Prólogos con un prólogo de prólogos.

Buenos Aires : Torres Agüero, 1975, pp. 13-14.

Borges, Jorge Luis. [1980]. « Homenaje a Victoria Ocampo »

, Discurso pronunciado en la Unesco el 15 de mayo de 1979, recogido enBorges enSur(1931-1980).

Buenos Aires : Emecé, 1999, pp. 326-331.

Borges, Jorge Luis.Jorge Luis Borges selecciona lo mejor de Paul Groussac

. Buenos Aires : Editorial Fraterna, 1981.

Borges, Jorge Luis.Euvres Complètes

I, ed. de Jean-Pierre Bernès. París : Gallimard, Col. « Bibliothèque de La Pléiade », 1993.

Borges, Jorge Luis.Obras completas(OCI - IV). Barcelona : Emecé, 1996

Borges, Jorge Luis.Textos recobrados. 1919-1929. Buenos Aires : Emecé, 1997.

Borges, Jorge Luis.

Cartas del Fervor. Correspondencia con Maurice Abramowicz y Jacobo Sureda (1919-1928) , ed. de Carlos García, trad. de Marietta Gargatagli. Barcelona : Galaxia Gutenberg, Círculo de lectores, Emecé, 1999.

Borges, Jorge Luis.Autobiografía 1899-1970

, Traducción de Marcial Souto y Norman Thomas di Giovanni. Buenos Aires : El Ateneo, 1999b.

Borges, Jorge Luis.Borges enSur. 1931-1980.Buenos Aires : Emecé, 1999c.

Borges, Jorge Luis.El círculo secreto.Buenos Aires : Emecé, 2003.

Caillois, Roger. « Discours de réception de Roger Caillois », Académie française, 20 de enero 1972

[En línea], consultado el 10 de junio de 2014. URL : http://www.academie-francaise.fr/discours-de-reception-de-roger-caillois).

Caillois, Roger. « Discurso de Roger Caillois »,en

Roger Caillois y la Cruz del Sur en la Academia Francesa,

traducción de Victoria Ocampo. Buenos Aires : Sur, 1972b : 21-64.

Camenen, Gersende. " Las armas y las lenguas. Borges y la Gran Guerra »,Cuadernos LIRICO

[En línea], (2014) : 11. Consultado el 14 de julio de 2014. URL :http://lirico.revues.org/1788

Carricaburo, Norma.El voseo en la literatura argentina.Madrid : Arco, 1999.

Charbonnier, Georges. [1965]. « Entretien avec Jorge Luis Borges : Approche de Jorge Luis Borges "

France Culture[En línea], consultado el 1 de junio de 2014. URL :https://www.youtube.com/ watch $? \mathrm{v}=\mathrm{qT} \_\mathrm{i} 9 \mathrm{tNbnjE}$

Costa Álvarez, Arturo.Nuestra lengua. Buenos Aires : Sociedad Editorial Argentina, 1922.

Costa Álvarez, Arturo.El castellano en la Argentina

. La Plata : Talleres de la escuela San Vicente de Paul, 1928.

Degiovanni Fernando y Toscano y García, Guillermo. « "Las alarmas del doctor Américo Castro" : institucionalización filológica y autoridad disciplinaria

",Variaciones Borges30 (2010) : 3-42. 
De Torre, Guillermo. « Victoria Ocampo, memorialista », en

Tres conceptos de la literatura hispanoamericana.Buenos Aires : Losada, 1951, pp. 96-114.

Di Tullio, Angela. « Otras lecturas de Borges : desde la gramática al idioma de los argentinos », en Jornadas InternacionalesBorges lectoren la Biblioteca Nacional

. Buenos Aires : Ediciones Biblioteca Nacional, 2013, pp. 69-79.

Glozman, Mara y Lauria, Daniela.«

La cuestión de la lengua nacional en la Argentina : apuntes para la lectura de los materiales de archivo ", en

Voces y ecos. Una antología de los debates sobre la lengua nacional (Argentina, 1900-2000).

Buenos Aires : Libros del Museo/ Ed. Cabiria, colección Oximoron, 2012, pp. 5-26.

Gómez López Quiñones, Antonio. « Borges, el hispanismo y la política del idioma » , en Juan Pablo Dabove (ed.) Jorge Luis Borges : Políticas de la literatura

. Instituto Internacional de Literatura Iberoamericana : Universidad. de Pittsburg, 2008,

pp. 157-175.

Gothot-Mersch, Claudine.

"Sur le renouvellement des études de correspondances littéraires : l'exemple de Flaubert », Romantisme72 (1991) : 5-29.

Groussac, Paul. «A propósito de americanismos », enAnales de la Biblioteca Nacional , Imprenta Coni Hermanos, tomo I, Apéndice II (1900) : 385-417.

Kristal, Efraín.Invisible work. Borges and Translation.Nashville : Vanderbilt University Press, 2002.

Lafon, Michel.Borges ou la réécriture.Paris : Seuil, 1990.

Lafon, Michel.Une vie de Pierre Ménard. Paris : Gallimard, Col. Blanche, 2009.

Louis, Annick. « Postface. Borges mode d'emploi français »,

Borges face au fascisme 2. Les fictions du contemporain

. Montreuil : Aux lieux d'être, 2007, pp. 313-329.

Molloy, Sylvia.La diffusion de la littérature hispano-américaine en France au XXsiècle.Paris : PUF, 1972.

Ocampo, Victoria. « Palabras francesas »,Sur,año 1 (1931) : 7-25, recogido en

Testimonios. Primera serie 1920-1934. Buenos Aires : Ediciones Fundación Sur, 1982, pp. 15-32.

Ocampo, Victoria. [1933]. « El cementerio marino»

, Conferencia en la Sociedad de Amigos del Arte, recogida enTestimonios. Primera serie 1920-1934

. Buenos Aires : Ediciones Fundación Sur, 1982, pp. 257-272.

Ocampo, Victoria. « Racine et Mademoiselle »,Testimonios segunda serie

. Buenos Aires : Sur, 1941, pp. 171-192.

Ocampo, Victoria.« Paul Valéry (1871-1945)», enTestimonios tercera serie. Buenos Aires : Sur, 1946, pp. 113-146.

Ocampo, Victoria.Soledad sonora. Buenos Aires : Sudamericana, 1950.

Ocampo, Victoria.Diálogo con Borges. Buenos Aires : Editorial Sur, 1969.

Olea Franco, Rafael. « La definición de la lengua », enEl otro Borges. El primer Borges.

Buenos Aires : FCE/El Colegio de México, 1993, pp. 175-216.

Oviedo, Gerardo, « Luciano Abeille y el idioma nacional de los argentinos », en

Luciano Abeille. Idioma nacional de los argentinos.

Buenos Aires : Colihue/Biblioteca Nacional, 2005, pp. 11-88. 
Philippe, Gilles, y Piat, Julien.

La langue littéraire. Une histoire de la prose en France de Gustave Flaubert à Claude Simon.

Paris : Fayard, 2009.

Prieto, Adolfo.El discurso criollista en la formación de la Argentina moderna

. Buenos Aires : Sudamericana, 1988.

Prieto, Julio. « Pierre Menard, traductor de Valéry : entre muertes del autor ».Variaciones Borges

29 (2010) : 53-76.

Saer, Juan José. « Borges francófobo ».Punto de vista(1989) 36: 21-24.

Sarlo, Beatriz. « Vanguardia y utopía », enUna modernidad periférica : Buenos Aires 1920-1930

. Buenos Aires : Nueva Visión, 1988 : pp. 95-120.

Sarlo, Beatriz. « Oralidad y lenguas extranjeras. El conflicto en la literatura argentina durante el primer tercio del siglo XX

».Orbis TertiusI, 1 (1996) : 167-178.

Terán, Oscar. « Ernesto Quesada : sociología y modernidad », en

Vida intelectual en el Buenos Aires fin-de-siglo (1880-1910). Derivas de la "cultura científica".

Buenos Aires : FCE, 2000, pp. 207-287.

Vegh, Beatriz. « Borges y Villiers de l'Isle-Adam : omisiones y énfasis », enBorges-Francia

, Cámpora, Magdalena y González, Javier Roberto (eds.). Buenos Aires : Publicaciones de la

Facultad de Filosofía y Letras, UCA, 2011, pp. 411-418.

Willson, Patricia.

La Constelación del Sur. Traductores y traducciones en la literatura argentina del siglo XX.

Buenos Aires : Siglo XXI Editores, 2004.

\section{NOTAS}

1.

El discurso será de inmediato publicado en Buenos Aires por Victoria Ocampo, en un opúsculo

llamado

Roger Caillois y la Cruz del Sur en la Academia Francesa

(1972b : 21-22) : «Durante mi adolescencia he cultivado una especie de odio por la literatura misma ; preveía y deseaba ingenuamente su próximo fin. [...] Sin embargo, en esas intransigencias de juventud en que la pasión contaba más que la lucidez, se encontraban reunidos ya, sin saberlo, varios elementos que más tarde se me revelarían decisivos : en primer lugar, una intención, más aun, un fervor por el idioma, que rodeaba de cuidados casi filatélicos, como diría Jorge Luis Borges ». La cita de Borges, por su parte, pertenece al ensayo « Las Kenningar », que Caillois tradujo en 1958 y publicó en

Histoire de l'infamie, Histoire de l'éternité(trad.

Roger Caillois y Laure Guille, Éditions du Rocher, Monaco, 1958). Borges habla de « un placer casi filatélico » ([1936] $1996: 371)$.

2.

Las « Autobiographical Notes », un diálogo con Norman Thomas Di Giovanni originariamente publicado en

The New Yorker(19 de septiembre 1970), es reeditado ese mismo año en la edición en inglés de 
The Aleph and Other Stories. 1933-1969

(New York, Bantam Books, 1970) con el nombre de « Autobiographical Essay ». Las citas en inglés están tomadas de esta edición.

3.

Para un análisis contrastado de esta operación de asimilación, ver Sylvia Molloy (1972 : 194-237) y Annick Louis (2007 : 313-329).

4.

Pueden consultarse al respecto los trabajos de Terán 2000, Oviedo 2005, Glozman y Lauria 2010,

Alfón 2013.

5.

«El idioma de los argentinos » es inicialmente una conferencia que Borges dicta en el Instituto

Popular de Conferencias el 23 de septiembre de 1927, publicada al día siguiente en el diario La Prensa. Borges la incorpora luego al libro de ensayos que toma su nombre,

El idioma de los argentinos(Buenos Aires, Manuel Gleizer editor, 1928).

6. Los textos de los románticos compilados por Fernando Alfón en su antología sobre La querella de la lengua en Argentina

(2013 : 73-169) ofrecen un comprehensivo panorama de estos textos programáticos.

7.

El desprecio de Borges por « la imaginaria cultura indígena » está en consonancia con la visión de las élites del siglo XIX respecto de lo que el « sujeto nacional » debía ser. Tal como señala Oscar Terán, « en América, como en tantas otras partes del mundo occidental, se consideraba que los nativos no eran un material asimilable a la modernidad, llamada entonces "civilización" » (2000 :

226). La permanencia, sin asomo alguno de problematización, en el año 1975, de esa visión en Borges queda evidentemente abierta al examen crítico.

8.

Arturo Costa Álvarez fue un traductor, filólogo y lingüista autodidacta que en 1922 publica, en La Plata, un largo ensayo llamado

Nuestra lengua

, quizás el primer esfuerzo global por historizar la cuestión de la lengua en la Argentina. Tras un inicial repaso de las posiciones sobre la lengua de los « prohombres de la primera generación argentina » -Echeverría, Alberdi, Sarmiento y Gutiérrez- Costa Álvarez expone sus propias ideas sobre el tema, en línea con las de Groussac y Cané : defensa de un castellano de registro culto, unidad de su uso, rechazo de un idioma nacional con rasgos propios, desprecio por todo proceso de « contaminación » o « corrupción » de la lengua por la inmigración, rechazo violento de las tesis autonomistas de Abeille. Inicialmente saludado por el campo intelectual, Costa Álvarez será desplazado del ámbito científico a partir de la institucionalización de la disciplina lingüística con la creación del Instituto de Filología, y la aparición en el campo intelectual de figuras como Américo Castro o Amado Alonso, filólogos españoles discípulos de Menéndez Pidal justamente convocados por Rojas para dirigir el Instituto. Para un documentado y fino análisis de este proceso de deslegitimación, véase Degiovanni y Toscano y García (2010).

9.

Di Tullio (2013 : 69) señala con razón que la elección de Costa Álvarez como referencia bibliográfica marca, por parte de Borges, un « imprevisible y coyuntural apoyo » a una voz ya marginalizada en el campo intelectual de la época. El gesto del futuro editor del sello « Oportet \&

Haereses » no es, por lo demás, demasiado sorprendente a la luz de su poética. Para un convincente desarrollo sobre las inesperadas y posteriores coincidencias de Borges con Américo

Castro, en la década del setenta, en relación a la lengua popular, las masas, el peronismo y su supuesto efecto « corruptivo » sobre la lengua, véase Antonio Gómez López Quiñones (2008:

168-172). 
10.

La idea según la cual la posesión del idioma es un derecho y un deber es un ejemplo, entre varios otros posibles. Véase al respecto Costa Álvarez (1922 : 73) y Borges ([1927], en Alfón 2013 :

269-270)

11.

«El idiomólogo es un tipo de escritor que no existe sino en la tierra americana descubierta, conquistada, colonizada y explotada por los españoles. Se distingue de todos los escritores de la humanidad por este rasgo característicos : predica la sustitución de la lengua en que escribe, y el castellano le sirve para decir que el castellano no sirve » (1922 : 91).

12.

Es interesante observar cómo el libro de Costa Álvarez contiene simultáneamente el mito de la claridad de la lengua francesa y su contradiscurso. Ver $1922: 108-109 ; 242 ; 295$.

13.

Costa Álvarez intentará incluso eximir a las grandes figuras del siglo XIX del sayo de « idiomólogos » (1922 : 91-92). Ver al respecto Alfón (2013 : 45-48).

14.

Como señala la crítica (Oviedo 2005 : 11-20 ; Alfón 2013 : 33-36), el libro es el primero en inscribir la polémica en torno al hipotético idioma de los argentinos en el ámbito supuestamente objetivo y científico de la filología, y no ya exclusivamente -como lo estaba en el siglo XIX- en la arena política. Para un análisis de los usos y

enjeux

políticos del estudio filológico del castellano en la Argentina, ver en cambio Degiovanni y Toscano y García (2010 : 21-34).

15.

Abeille, siguiendo a Humboldt, considera que las lenguas reflejan y se adaptan al « genio » de los pueblos que las hablan (ver Oviedo $2005: 14$ ).

16.

La presentación que hace Costa del libro de Abeille es perfectamente precursora del « Arte de injuriar »: « Las 428 páginas que contiene

Idioma Nacional de los Argentinos

por Luciano Abeille, doctor en teología, pueden dividirse en tres partes iguales, correspondientes a los tres temas que en ellas trata el autor promiscuamente : una parte comprende la exposición y análisis de los hechos confirmativos de la teoría que ha inspirado el libro ; otra parte, 140 páginas, está dedicada a presentar al autor como entendido en lingüística ; en la tercera parte restante hay 100 páginas de homenaje a los argentinos [...] es evidente que la obra ha sido escrita con tres propósitos : plantear y demostrar una tesis, ostentar erudición y hacernos zalamerías [...

$$
\text { ]» }(1922: 107) \text {. }
$$

17.

Costa Álvarez ofrece un florilegio de los ataques más fuertes (1922 : 117-125). Las respuestas de Groussac («A propósito de americanismos », [1900] $2013: 212-216)$ y de Cané (" La cuestión del idioma », [1900] 2013 : 216-223) pueden leerse en la antología de Alfón. Para un análisis de esta violenta recepción de un libro que luego caerá en el olvido, así como para una clara sinopsis de las tesis de Abeille, ver Oviedo (2005 : 12-32). Para una recontextualización del campo intelectual que polemiza sobre las relaciones entre sujeto nacional, lengua e inmigración en el fin de siglo, ver Terán 2000 : 207-287.

18.

Juan B. Terán, « Naturaleza de la lengua » (1908), recogido en Alfón 2013 : 232. Costa Álvarez cita la frase en su alegato en contra de Abeille (1922 : 121-122).

19. La cita la hace Costa Álvarez (1922: 122).

20. La expresión es de Paul Verdevoye, citado en Oviedo 2005 : 32. 
21. Véase Prieto 1988, Sarlo 1996, Carricaburo 1999, Terán 2000.

22. Ver al respecto Terán 2000 : 254-259; Lauria y Glozman 2012 : 20-21.

23.

"Sobre el meridiano de una Gaceta » ([1927] 1997 : 303). La obsesión también cunde, sin embargo, en Buenos Aires, si nos guiamos por la edición, en 1941, de la « primera edición argentina ampliada »delDiccionario de galicismos

(Buenos Aires, Joaquín Gil editor, 1941, 832 p.) del venezolano Rafael María Baralt (1855), inicialmente publicado en Madrid. Baralt fue el primer latinoamericano en ocupar un sillón de número en la Real Academia Española.

24.

Ver al respecto Rosemblat (1961) y Glozman y Lauria (2012). La perspectiva persiste, diluida, en Arturo Costa Álvarez, para quien la morfología de las lenguas acompaña « en sus formas cada vez más complejas a la evolución perenne de las ideas y los sentimientos

$》(1922: 290)$.

25.

En « El idioma infinito » : « Alguien dirá que ya es millonario el lenguaje y que es inútil atarearnos a sumarle caudal. Esa agüería de la perfección del idioma es explicable llanamente : es el asombro de un jayán ante la grandeza de un diccionario y ante el sinfín de voces enrevesadas que incluye. Pero conviene distinguir entre riqueza apariencial y esencial (

1925 : 35-36). En «El idioma de los argentinos »

: «Abre el patán y el que no es patán nuestro diccionario y se queda maravillado frente al sinfín de voces que están en él y que no están en ninguna boca

》(1928 : 228).

26. Escribe Costa : « Habría que averiguar si en el diccionario francés están las delargot , como están en el castellano las de germanía, y si aquél contiene los obsoletismos y los provincialismos que plagan a éste ; si [...] figuran como del lenguaje común los innumerables términos heráldicos, náuticos, coreográficos, de esgrima y de montería [...] que la Academia española presenta en su léxico como de uso corriente fuera de sus respectivos círculos [...] Y si, después de esto, se descartara también del diccionario de la Academia española el gran número de extranjerismos, principalmente galicismos, que el uso ha impuesto en nuestra lengua y que esa corporación ha debido sancionar, habría que preguntar, como hace Toro y Gómez en Por la cultura y por la raza, "a qué queda reducido ese fabuloso saldo a favor nuestro" »

(1922 : 293-4). Ver también, enEl castellano en la Argentina,

los ataques en contra de los « vicios orgánicos "y la « hipertrofia del vocabulario » del diccionario de la Real Academia (1928: 36).

27.

Véase también «El idioma de los argentinos» : «La sueñera mental y la concepción acústica del estilo son las que fomentan sinónimos : palabras que sin la incomodidad de cambiar de idea, cambian de ruido

»(1928 : 228). Ese « ruido»

, en español, es, para el Borges de los años veinte, « sermonero y enfático »

, debido al predominio de las vocales en español, « que por ser pocas, cansan »

(1928 : 235). La crítica reaparece en « Las alarmas del doctor Américo Castro »

: «El hecho es que el idioma español adolece de varias imperfecciones (monótono predominio de las vocales, excesivo relieve de las palabras

([1941] 1996 : 32-33). Originariamente, si seguimos al propio Borges ([1961] $1996: 53)$, el desinterés que roza con el desprecio por la sonoridad de la lengua viene de Macedonio : «Otra razón de su facilidad literaria era su incorregible menosprecio de las sonoridades verbales y aun de la eufonía. No soy lector de soniditos 
, declaró alguna vez, y las ansiedades prosódicas de Lugones o de Darío le parecían del todo vanas ".

Para un análisis de este desprecio del significante en Macedonio, y su impacto en Borges, véase el trabajo de Daniel Attala (2014 : 153-157 y 170-174).

La anécdota viene de una entrevista de Reina Roffé en 1982 : «RR - ¿Usted fue amigo de Arturo Capdevila, él hablaba de una forma muy castiza, no ?J.L.B -Capdevila, no sé por qué, había tomado como modelo a los personajes del teatro español del siglo XIX. Decía cosas que nadie decía. Una vez fui a su casa, estaban por servir el té. Capdevila dijo : "Viva Dios, pronta está (o

lista está) la merienda"

. Aparece aquí la clásica estrategia borgeana que consiste en descalificar un problema descontextualizándolo de su campo polémico («Capdevila, no sé por qué...

»). La entrevista puede leerse en línea [http://www.literaturas.com/entrevistaBorges.htm]

28.

Ricardo Rojas, y Américo Castro, « Instituto de Filología : Discursos pronunciados por el decano don Ricardo Rojas y por el profesor don Américo Castro en el acto inaugural, realizado el día 6 de junio de 1923

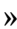

, Buenos Aires, Instituto de Filología, Universidad de Buenos Aires, citado por Fernando Alfón $(2013: 50)$

29. «El idioma infinito »

(1925a : 36) : « Dos conductas de idioma (igualmente tilingas e inhábiles) se dan en esta tierra [...] ».«El idioma de los argentinos »

(1928 : 224) : « Dos influencias antagónicas entre sí militan contra un habla argentina [...]».

30.

Este solapamiento se encuentra en el inicio mismo de la cuestión sobre la lengua. En 1828, Juan Cruz Varela publica en

El Tiempoun ensayo llamado « Literatura Nacional»

en el que une el desarrollo de la literatura nacional con el conocimiento profundo del « idioma en que hablamos

». Ver al respecto Alfón (2013: 13).

31.

Como lo han analizado Arnoux y Bein (1997), Borges clausura su participación en la discusión sobre el « problema

del idioma nacional en 1941, con el inicio de la asesina reseña del libro de Américo Castro (que luego publicaría en

Otras inquisicionesbajo el título « Las alarmas del Doctor Américo Castro »

). Borges desarma la problemática del supuesto idioma privativo al transformar la noción de "problema" en petición de principio (que justamente inventa el problema como tal), y al armar la incómoda analogía, en el año 1941, entre el « problema de la lengua "y el « problema judío »

: « [...] así como enunciar el segundo es autorizar la masacre, referirse al primero en esos términos es hacer posible cualquier ataque a la identidad lingüística $y$, por lo tanto, nacional de un pueblo

(Arnoux y Bein 1997 : 25). Para un análisis del efecto que esta analogía podía tener sobre la legitimidad de los filólogos españoles antifranquistas que se ocupaban del «problema de la

lengua 
en la Argentina, ver Degiovanni y Toscano y García (2010). Véase también, para la descripción de la estrategia retórica que consiste en inventar problemas para luego imponer soluciones decididas de antemano, y del uso que Borges hace de ella en su denuncia del antisemitismo, el análisis que Annick Louis (2006 : 173-184) le dedica al « pseudo-problème des juifs »en suBorges face au fascisme

. Nótese, por último, que el recurso retórico del « problema inventado » reaparece al inicio de « El escritor argentino y la tradición ».

32.

Para un relevamiento del uso de esos procedimientos en la obra borgeana, ver Barrenechea

(1953: 563-566).

33.

Las modificaciones léxicas se ven reforzadas por calcos ortográficos que remedan la oralidad rioplantense (« realidá

$\gg$

). Sarlo (1988 : 117) señala con razón que las propuestas de innovación en la ortografía se originan en « escritores seguros de su fonética y de su origen. Sería impensable entre los recién llegados al campo intelectual, de ortografía indecisa, como Arlt, o para quienes la práctica de la escritura es una adquisición costosa y reciente

".

34.

Ver sin embargo este comentario sobre un calembour de Groussac, que juega con la composición de palabras : « [...] acuñó la palabra japonecedades, que sin duda habrá pensado en francés :japoniaiseries »(2003:196).

35.

Olea Franco (1993 : 186-190) ofrece un detallado análisis de esas innovaciones lingüísticas en el poemario.

36.

Particularmente grata debe haberle resultado a Costa, que se encontraba entre el público, la mención de su nombre en la conferencia sobre «El idioma de los argentinos ».Degiovanni y Toscano y García (2010 : 13) reproducen el suelto deLa Prensa

, del 24 de septiembre de 1927,

que relata el encuentro y enumera a los demás notables presentes, entre los cuales se encontraba

37.

Alfonso Reyes.

Había escrito Costa Álvarez enNuestra lengua

: «Según un paciente cómputo hecho por el académico español conde de Casa Valencia, el

diccionario de la Academia española (ed. 1899) registra 59227 palabras, y el de la Academia

francesa (ed. 1877) contiene 30695 solamente. De esto podría deducirse que los que se expresan en la lengua castellana están en condiciones de hacerlo con más variedad que los franceses en su idioma ; pero sería un error afirmar que, por lo tanto, se expresan con más perspicuidad, con más elocuencia o con más desenvoltura. Bien dice Olive en su

Diccionario de sinónimos

que « la pluralidad de voces y palabras no prueba mayor o menor riqueza de las lenguas » (1922 : 293).

38. El argumento reaparece, sin mención de Costa Álvarez, en « El idioma de los argentinos » (1928: 230-231).

39.

Una « lengua oral de criollos viejos urbanos»

, « corpus familiar y masculino, nunca vulgar o canalla »

(Sarlo 1988 : 118). Véase también Olea Franco (1993 : 194-195), Degiovanni y Toscano y García

$(2010: 16)$. 
40.

Ver al respecto Olea Franco (1993: 194-195) : «Borges desea trabajar literariamente la oralidad bonaerense, pero debido a sus profundas raíces criollas, rechaza cualquier influencia "extranjeriza" : por ejemplo, hay que buscar minuciosamente para encontrar algún "italianismo" en su escritura. [...] La oralidad que maneja remite, más bien, a la lengua criolla, no contaminada con expresiones foráneas

41.

El texto, que ya había sido publicado en el diarioLa Nación en 1903, es una respuesta airada a un artículo de Loyson-Bridet -alias Marcel Schwob- sobre errores « gramaticales y literarios »de periodistas argentinos (1922: 323-340).

42.

Ver al respecto la diatriba en contra del « genio » de los escritores españoles en «El idioma de los argentinos »

y, veinticuatro años más tarde, en "El escritor argentino y la tradición", las observaciones sobre España como « gusto adquirido

", " prueba de la versatilidad argentina "y no de una " capacidad heredada »

([1941] 1996 : 272). Borges entiende que las grandes literaturas no dependen de la naturaleza intrínseca de una lengua, sino del uso y la tradición que ésta acarrea a lo largo de los siglos. El singular diagnóstico que hace del español es, en este sentido, elocuente : la lengua es grande, no así sus realizaciones peninsulares. Véase por ejemplo el

Borgesde Bioy :BORGES :

«El español tiene mayor pureza de sonidos que otras lenguas. Está libre de la ü del francés, del exceso de consonantes del inglés. Es un idioma excelente : yo observo tan sólo que no produjo tantos escritores buenos como el francés o el inglés

(2006 : 900). Para un análisis de la relación de Borges con el hispanismo, ver Antonio Gómez López-Quiñones (2008).

43.

Refrenda Guillermo de Torre : « La vida mental de Victoria Ocampo transcurrió de modo exclusivo en un idioma prestado, en francés, durante varios años de su vida. Concretamente, hasta el conocimiento de José Ortega y Gasset, en 1916, durante el primer viaje del filósofo a la Argentina, hasta que este le descubrió que todo podía decirse en lengua española, sin por ello volverse automáticamente pesado, afectado, grandilocuente

(1951 : 110). De Torre - ¿es necesario recordarlo ?- es el elemento disparador de la polémica en torno al « meridiano intelectual de Hispanoamérica

, con su propuesta de un hispanismo centralizador que, paradójicamente, niega todas las convicciones de Ocampo. En el polémico editorial publicado en 1927 en

La Gaceta Literaria

había por ejemplo escrito : «[...] puede afirmarse paladinamente que todos los mejores valores de ayer y de hoy -históricos, artísticos, de alta significación cultural- que no sean españoles, serán autóctonos, aborígenes, pero, en modo alguno, franceses, italianos o sajones ".

44.

« Venga a ver lo nuestro »

, le dice a Caillois cuando lo invita antes de la guerra, « Usted dará conferencias. Nosotros le daremos páramos y montañas de piedra hasta hartarlo [...] En junio de 1939, llegó a Buenos Aires con las conferencias en su cartapacio ; yo lo esperaba con la pampa y los Andes en el mío 
(1972 : 14). Y a Drieu la Rochelle : « América no trae nada nuevo al mundo, insistía Drieu. Está tan podrida como nosotros. Muchas razones tendríamos para creerlo, le decía yo ; pero basta una para no creerlo del todo : somos americanos. Lo que sólo ha comenzado a existir no puede ya estar en su fin 》(1950 : 40).

45. Por ejemplo este diálogo narrado en elBorgesde Bioy Casares : « BORGES

: Victoria me trajo una vez un poema de no sé quién paraSur

y me preguntó : ¿Qué tal es ?". Yo le dije : ¿Y a usted qué le parece ?". "Yo no entiendo los poemas en español", me contestó.

BIOY :"Tampoco en otros idiomas."BORGES : "

Es claro, debí decirle : "¿Por qué esa modestia ? ¿Por qué esa limitación ? Su incomprensión es enciclopédica"

"(2006:1184-5).

46.

Las citas en castellano están tomadas de la traducción de Norman Thomas Di Giovanni y Marcial Souto del « Autobiographical Essay

» :Autobiografía. 1899-1970(1999b).

47. Ver al respecto Saer (1989: 22-24); Lafon (1990: 60-62); Balderston (1993: 18-33); Prieto 2010.

48.

Es interesante notar cómo los mismos rasgos de afectividad se repiten en los textos donde Ocampo evoca a Valéry, y cómo su figura tutelar está unida a cierta idea de la lengua francesa : una lengua que es refugio y protección ; una lengua estricta, de pensamiento. Estas ideas también aparecen en las consideraciones de Caillois (1972) sobre el francés y sobre Valéry.

49.

Borges, carta 22 a Abramowicz $(1999$ : 22, 140). Retomamos en este apartado parte del desarrollo expuesto en el colectivo sobre intercambio epistolar transatlántico coordinado por Ana Gallego Cuiñas y Erika Martínez : «

Cenáculos, sectas, batallas incruentas

. Sobre la correspondencia en francés de Borges (1919-1921) ", en

Queridos todos : el intercambio epistolar entre escritores hispanoamericanos y españoles del siglo XX

, Berna, Peter Lang, 2013, pp. 193-206. Citaremos las cartas tal cual están numeradas (y seguidas por el número de página) en las

Cartas del fervor. Correspondencia con Maurice Abramowicz y Jacobo Sureda (1919-1928)(1999).

50. Borges (1939 : 446).

51.

« La materia principal era el latín, y pronto descubrí que si uno era bueno en latín podía descuidar un poco los demás estudios. Sin embargo, las otras materias -álgebra, química, física, mineralogía, botánica, zoología- se estudiaban en francés ; y ese año aprobé todos los exámenes excepto, precisamente, el de francés. Sin decirme nada, mis compañeros firmaron una petición al director. Señalaban que yo había tenido que estudiar todas las materias en francés, un idioma que también había tenido que aprender. Le pedían que lo tuviera en cuenta ; y él amablemente aceptó. Al principio ni siquiera entendía cuando un profesor me llamaba por mi apellido, porque lo pronunciaban a la manera francesa, con una sola sílaba. Cada vez que tenía que contestar, mis compañeros me daban un codazo

(Borges 1999b : 41-42). Jean-Pierre Bernès señala por su parte en la cronología para la edición Pléiade que Borges estudia francés con un profesor particular (Borges 1993 : XLII).

52.

Sobre las traducciones borgeanas de poemas del expresionismo alemán, ver Efraín Kristal (2002 :

41-46).

Cuadernos LIRICO, 12 | 2015 
53.

Para una lectura dialéctica del manejo de lenguas en Borges y su relación con la Primera Guerra Mundial, ver la estimulante hipótesis de Gersende Camenen (2014).

54 .

Borges se escribe regularmente con Abramowicz entre junio 1919 y marzo 1921. Las cartas, después del primer regreso a Buenos Aires, se espacian. La edición de Galaxia Gutenberg añade una última carta de septiembre 1928.

55.

La anécdota fundadora de la juvenilia aparecerá luego en todas partes : entrevistas y diálogos de Borges con periodistas, cronologías, biografías. « Mis dos amigos íntimos, Simón Jichlinski y Maurice Abramowicz, eran de origen judío-polaco. Uno llegó a ser abogado y el otro médico. Les enseñé a jugar al truco y aprendieron tan rápido y bien que al final de la primera partida me dejaron sin un centavo »(1999b : 42-43).

56. La lista de amigos está a su vez escrita entre paréntesis. «Paréntesis pasional »,Grecia , año 3, n 38, 20 de enero de 1920, recogido en $1997: 27$.

57. Grecia

, Madrid, año 3, n 46, 15 de julio de 1920, recogido en $1997: 51$ : «Cuántas noches maduras / se desgajaron sobre nuestra frente hermano / Fuimos abriendo como ramas las calles / Nuestras risas rodando se rompieron / frescos juguetes en los cristales del fondo / Tus manos beben el cercano silencio / Las melopeas / El piano late como un torrente enyugado / Tus manos arden en

la luz de los sones / Alguien / junto al farol decapitado / ha de ceñirnos un collar de estepas

58. Sobre el pseudónimo de Abramowicz, ver Borges 1999 : 120 (carta 17 a Abramowicz : « La Ultima horaoù, dans ma prose défensive de notre religion littéraire, s'étale ton pseudonyme »

). Con ese pseudónimo firma sus contribuciones en las publicaciones ultraístas y es mencionado por Borges en los textos programáticos. Ver al respecto « La metáfora »(1997 : 118) y « Ultraísmo »(1997 : 131).

59. Sur, año 14, $\mathrm{n}^{\circ} 118$, agosto 1944 , p. 7-12, recogido en 1996 :516-517.

me.

Sobre un joven profesor sevillano: «[...]

Il veut qu'en art on suive "les saines traditions classiques". Il ressemble auJournal de Genève » $(13,102)$.

60.

Borges transcribe esforzada y humorísticamente un diálogo con un español que lo interroga sobre Suiza : « Le Jeune homme : Il doit y avoir beaucoup de montagnes par là. Moi : Oh oui. Le J.

H. : La Suisse est le pays le plus mont accidenté de [sic] l'Europe [...] L'horlogerie est le seul commerce d'exportation que fait la Suisse, pas [sic]?

Moi : Il y a aussi le chocolat » $(1,60)$. Es interesante la tachadura mont (que probablemente remite a "montagneux") en cuanto quizá delata el esfuerzo por evitar aparentes hispanismos (sin embargo "montagneux" hubiera funcionado en esta frase).

61.

«Clarita, la querida del médico, a, elle, une sans-façon qui déconcerte » $(11,93)$. « Le señor s'est gardé d'exprimer une réponse quelconque. Muet comme huître [sic], le señor escoliasta a gardé sus palabras idiotas pour meilleure occasion ".

$(18,124)$. [Sobre Elviro Sanz, autor de un ataque a la revistaGrecia

al que Borges contestó con vehemencia con una« Réplica »en el diario mallorquínUltima Hora-1997 : 71.$]$

62. Borges reseña libros de Pío Baroja (Momentum Catastrophicum), de Azorín (

Entre España y Francia) y de Ramón Ruiz Amado, jesuita y “auteur d'une histoire universelle ad usum scholarum

Cuadernos LIRICO, 12| 2015 
" : « Dans ce livre, il s'agit de ramener à l'Église les libertins et les âmes perverties par les arguments de Voltaire. Il est bien curieux de constater que dans un pays où seuls quelques érudits connaissent le

Dictionnaire Philosophique,

ce pauvre Arouet continue à être l'épouvantail, la bête noire des pieuses gens ».

63. Borges comenta el poema de Abramowicz en la carta 16 (p. 114) : « Quelque chose dans un chant résigné

-l'allure, le rythme- me rappele [sic] Hölderlin, poète qui t'est, je crois, totalement inconnu ».

El poema y su traducción se reproducen en $1997: 147$.

64. $\quad$ Me dejaron tan solo / y con todas las horas en las manos ", escribe Sureda. Borges traduce : « Ils me laissèrent si seul / toutes les heures dans les mains » (13, 104-105).

En dos cartas a Sureda menciona Borges el poema $(2,163$ y 3,164$)$.

65.

Ver por ejemplo la carta a Sureda del 4 de octubre de $1920(3,164)$ : «Tu poema aquel de las líneas estupendas "me dejaron tan solo / y con todas las horas...

"ya debe estar en la custodia del Porta-estandarte [Vando Villar

] a quien se lo mandé. Le mandé también una copia al otro prosélito que he traído yo alultra

, al lírico ironizante judío Maurice Claude. Este -desde Ginebra- te transmite sus felicitaciones, sirviendo yo de hilo conductor

66.

«Jules Supervielle",Sur

, n² 267, noviembre-diciembre de 1960 (recogido en Borges 1999c : 63-64).

67.

«Con un mínimum de habilidad, creo que lograremos armar una polémica en regla. Tú y yo -que somos las columnas de Hércules del ultra en estas tierras- no podemos tolerar las atrevidas y oportunas blasfemias de Laura de Lillot [

por « L'Aura de L'illot », pseudónimo de un crítico del ultraísmo

]. El martes subo a Valldemosa con la diligencia. Concertaremos un plan de campaña." (A Sureda,

$4,166)$.

68.

Tal es el nombre con que aparece la respuesta a un artículo de Elviro Sanz, firmado con el seudónimo « L'Aura de L'Illot

", atacando el ultraísmo. Ver al respecto $1997: 711-72$.

69.

Las maniobras y otras confabulaciones narradas por Borges a sus dos comparsas, tanto en francés como en español, se superponen en las siguientes cartas del epistolario a Sureda : 4, $166 ; 8$,

$170-171 ; 9,172$.

70.

Ver justamente cómo, por ejemplo, el propio Arturo Costa Álvarez descalifica a Américo Castro al reseñar

El problema del bien diccionario(1923)enEl castellano en la Argentina

: «Serie de artículos periodísticos (vale decir : unconsomméde lugares comunes concroutes

de actualidad) cuya substancia se reduce a las conocidas generalidades sobre los méritos ideales y los defectos reales de los diccionarios de la lengua castellana $»(1928: 23)$

71.

Véase por ejemplo las hipótesis de Efraín Kristal (2002 : 111-113) sobre la homología estructural entre « Emma Zunz

"y « Le matelot d'Amsterdam » 
, de Apollinaire, cuento que Borges traduce en 1943, así como su lectura de « La torture par

l'espérance

»de Villiers de l'Isle-Adam, como antecedente genético de « La escritura del Dios »

(2002 : 122-124). Borges traduce el cuento de Villiers para laAntología de la literatura fantástica

(1940). Para un análisis sobre cómo Borges modifica, con sus elecciones de traducción, lo que él considera la retórica romántica de los franceses presente en el cuento de Villiers, ver el trabajo de Beatriz Vegh (2011 : 411-418).

\section{RESÚMENES}

Este artículo se propone analizar las distintas capas de la ambigua relación que Jorge Luis Borges mantiene con la lengua francesa a partir de su producción de los años veinte y treinta : el francés como punto de articulación en la reflexión sobre la naturaleza del castellano en la Argentina, en el marco de la histórica discusión sobre el idioma vernáculo ; como lengua de formación, de legitimación literaria y de pertenencia a un grupo ; como estrategia de diferenciación y de posicionamiento en el campo intelectual de la época de la fundación de Sur.

Cet article propose l'analyse du rapport ambigu que Jorge Luis Borges entretient avec la langue française à partir de sa production des années 1920 et 1930 : le français comme point d'articulation dans sa réflexion sur la nature de l'espagnol parlé en Argentine, dans le cadre de la polémique sur la langue qui eut lieu au tournant du siècle ; le français comme langue de formation, de légitimation littéraire et d'appartenance à un groupe ; le français comme stratégie de différenciation et de positionnement dans le champ intellectuel, à l'époque de la fondation de Sur.

This article analyzes the different layers of Jorge Luis Borges' ambiguous relation with French language in his production of the Twenties and Thirties : as a point of articulation in the discussion of the Spanish spoken in Argentina, during the historical language controversy that took place at the turn of the Century ; as a language of education, literary legitimization and group belonging; as a differentiation strategy and positioning in the intellectual field in the

Thirties, when Surwas founded.

\section{ÍNDICE}

Mots-clés: Jorge Luis Borges, langue française, polémique de la langue en Argentine, légitimation, stratégies de différenciation

Palabras claves: Jorge Luis Borges, idioma francés, polémica de la lengua en la Argentina, legitimación, estrategias de diferenciación

Keywords: Jorge Luis Borges, french language, language controversy in Argentina, legitimization, differentiation strategies 
AUTOR

MAGDALENA CÁMPORA

Universidad Católica Argentina

CONICET

magdalacampora@gmail.com 